\title{
The Credit Rating Crisis and the Informational Content of Corporate Credit Ratings
}

\author{
Mascia Bedendo, LARA CATHCART, Lina EL-JAHEl AND LEO Evans *
}

March 14, 2013

\begin{abstract}
There has been much scrutiny of the Credit Rating Agencies' (CRAs) flawed ratings of structured products in the build-up to the financial crisis. Our study examines whether the 'credit rating crisis' altered the information effects of their traditional product, corporate bond ratings. Using an event study, we analyze the Credit Default Swap (CDS) market's response to rating announcements by Moody's between September 2004 and December 2009. Our results demonstrate that CDS price effects were considerably greater in the pre-crisis era, and document a possible spillover effect of reputational damage onto the bond rating services of the CRAs.
\end{abstract}

JEL Classification Codes: G01, G14, G24

${ }^{*}$ All errors remain our own. Correspondence should be addressed to M. Bedendo Department of Finance, Universita’ Bocconi. Via G. Röntgen, 1 - 20136 Milan, Italy or L.Cathcart Imperial College Business School,South Kensington Campus, London SW7 2AZ, United Kingdom or L.El-Jahel The Business School, University of Auckland, Private Bag 92019, Auckland 1142, New Zealand or L.Evans J.P. Morgan Securities plc, 25 Bank street, Canary Wharf, London E14 5JP, United Kingdom Emails: mascia.bedendo@unibocconi.it, 1.cathcart@imperial.ac.uk, 1.eljahel@auckland.ac.nz, Leonard.a.evans@jpmorgan.com. 


\section{Introduction}

'They have no brand, they have no credibility whatsoever, I can't imagine any investor trusting them.' - U.S. Representative Christopher Shay - House Committee on Oversight and Government Reform: Credit rating agencies and the financial crisis. October 22, 2008.

On July 10, 2007, Moody's downgraded 399 Residential Mortgage Backed Securities (RMBS) with an original value of $\$ 5.2 b n$ and Standard \& Poor's placed 612 RMBSs with an original value of $\$ 7.3 b n$ on review for downgrade. The next day, Moody's placed a further $\$ 5 b n$ of Collateralized Debt Obligations (CDOs) on review for downgrade. These events marked the beginning of a series of mass downgrades of structured products throughout 2007, 2008 and 2009. According to the Financial Crisis Inquiry Commission, by June $2010 \$ 2.5 t r$ worth of RMBSs and $\$ 564 b n$ of CDOs had been downgraded. The scale of the resulting writedowns by financial institutions and the ensuing events led to a succession of public enquires in the U.S. that investigated the role of the CRAs in the financial crisis. The Senate Banking Committee, the House of Representatives' Committee on Oversight and Government Reform, and various other committees heard evidence. Given their findings, the Dodd-Frank Wall Street Reform and Consumer Protection Act, which was signed into law on July 21, 2010, has provisioned for new oversight of, and requirements for, the CRAs in order to enhance transparency and accountability within the rating industry.

Collectively these events, dubbed the 'credit rating crisis', have highlighted many shortcomings of the rating practises and business models of the CRAs, the structure of the credit rating industry and the regulatory framework around ratings. A rapidly growing literature has documented various aspects of these issues ${ }^{1}$. Among others, Benmelech and Dlugosz (2009) explain the structured finance collapse of 2007-2008; they cite inflated ratings due to ratings shopping and model error

\footnotetext{
${ }^{1}$ As has the mainstream media. For example 'AAA Oligopoly', 'The Ratings Racket' (Wall Street Journal 26 Feb. and 25 Jun., 2008 respectively) and 'Triple-A Failure' (New York Times 27 Apr., 2008).
} 
on behalf of the agencies as contributing factors. Coval, Jurek and Stafford (2009) investigate the rise and fall of structured finance and the challenges faced by CRAs, in terms of the required parameter and modeling assumptions, to arrive at accurate ratings. Brunnermeier (2009) also looks at the role of the CRAs and structured products in the financial crisis. White (2010) explains how the financial regulatory structure facilitated the systemic consequences of the failings of rating agencies.

Whilst the focus of the literature on the rating crisis has been on flawed structured product ratings, in this paper, we investigate its implications for corporate credit ratings. Our hypothesis is that this episode has negatively impacted on how market participants perceive bond ratings and their informational content. There are at least two motivating arguments as to why we believe this might be the case. Firstly, the unprecedented failings of structured product ratings may have had a spill-over effect and impaired the integrity of bond ratings. It must be noted that structured product rating symbols are the same as those on corporate and government bonds ${ }^{2}$; the credibility and widespread usage ${ }^{3}$ of bond ratings, in conjunction with the existence of ratings-based regulation, allowed structured products to be widely marketed and sold. It has been argued by Adelino (2009) that many investors in AAA-rated mortgage backed securities simply purchased the rating, relying on the symbols' connotation as implied by corporate and government bonds. As noted by Pagano and Volpin (2010), the CRAs were even explicit in reassuring investors that structured products ratings were directly comparable to those of traditional bonds:

'Our ratings represent a uniform measure of credit quality globally and across all types of debt instruments. In other words, 'AAA' rated corporate bonds should exhibit the same degree of credit quality as an 'AAA' rated securitized issue' - Standard \& Poor's (2007), Ratings Direct Research.

\footnotetext{
${ }^{2}$ Mason and Rosner (2007) explain the misapplication of such symbols in terms of why traditional bond ratings do not properly account for the risks in RMBS and CDOs.

${ }^{3}$ CRAs have been rating corporate bonds for over a century. Also bond ratings have a long history of empirical testing, through various stages of the economic cycle. See Perraudin and Taylor (2004) and references therein.
} 
Secondly, it is conceivable that the rating crisis could have impacted on how market participants perceive the incentives and or the ability of agency analysts to reliably produce timely, valuerelevant information about risk ${ }^{4}$. CRAs have enjoyed a considerable informational advantage over other participants; as studied by Jorion, Liu and Shi (2005) they have been exempt from the SEC's Regulation Fair Disclosure, which prohibits U.S. public companies from making selective, nonpublic disclosures to favored investment professionals ${ }^{5}$. As such, credit ratings include both public and private ${ }^{6}$ information. Yet ultimately, a corporate credit rating is a team of analysts' subjective assessment $^{7}$ about the overall financial capacity of a particular issuer to pay its financial obligations. Regardless of the contributing mechanisms, our hypothesis has the empirically testable implication that the price effects of corporate rating announcements will have decreased.

Using an event study, we investigate the information effects of Moody's corporate rating announcements by analyzing their influence on the CDS market prior to, and subsequent to the onset of the rating crisis. A CDS is a bilateral contract that transfers a defined credit risk between counter-parties. Using standard no-arbitrage arguments, Duffie (1999) shows that a firm's CDS spread is closely related to a par-coupon bond credit spread of the same maturity. However CDS spreads likely provide a better measure of the market prices of the risks that Moody's ratings aim to capture, probability of default and loss-given-default. We consider all six types of rating actions by Moody's: Review for downgrade, rating downgrade, outlook negative (negative events), review for upgrade, rating upgrade and outlook positive (positive events). Our sample consists of 542

\footnotetext{
${ }^{4}$ Bongaerts, Cremers and Goetzmann (2009) also suggests that people have questioned whether the structure of the credit rating industry provides the proper incentives for the production of reliable, value-relevant information about risk. Griffin and Tang (2010) show that CRAs deviated from their structured product rating models by including an element of subjectivity in ratings, the degree of which was positively related to future downgrades.

${ }^{5}$ Section 939B of The Dodd-Frank Act revises Regulation FD, deleting Rule 100(b)(2)(iii) which exempts credit rating agencies.

${ }^{6}$ Which may include an issuer's expansion plans, budget, future products and board meeting minutes as well as advanced notification of corporate events such as debt issuance and mergers. It might also include factors that are entirely subjective, such as management quality (See Moody's (2002)).

${ }^{7}$ CRAs have preferred to use the word 'opinion' in light of the first amendment protection of credit raters as publishers and credit ratings as opinions, which has effectively safeguarded them from litigation historically. However, the Dodd-Frank Act of 2010 repeals Rule 436(g) of the Securities Act of 1933. The CRAs may now be liable as 'experts'.
} 
announcements and daily spread data pertaining to 205 eminent U.S. issuers between September 14, 2004 and December 14, 2009.

We first examine the price effects of rating announcements during the pre-rating crisis period, September 14, 2004 to July 10, 2007. Our key finding is that downgrade reviews and upgrade reviews are found to have the largest impact on spreads; mean announcement day CDS responses are estimated to be $10.1 \%$ and $-6.1 \%$ respectively. Followed by downgrades $(3.3 \%)$ and upgrades $(-1.5 \%)$. In line with the large body of literature that has examined different security price responses to ratings announcements ${ }^{8}$, we find that some of the CDS price adjustment occurs before downgrade reviews in 'anticipation'; statistically significant increases in spreads of $4.7 \%$ can be identified a week in advance. Also, CDS prices fully adjust to the information in rating announcements within a day of the announcement; indicative evidence in support of the hypothesis that the CDS market is informationally efficient. We can relate these results to the extant literature that has studied the effects of announcements on CDS spreads. For instance, Hull, Predescu and White (2004) conclude that whilst the CDS market anticipates all three types of negative announcement, there are only announcement day effects for downgrade review. Norden and Weber (2004) find anticipation and announcement day effects for downgrade reviews and rating downgrades, yet insignificant reactions to positive announcements. In line with our results, they find no significant post-announcement spread movement. Micu, Remolona and Wooldridge (2006) suggest that all six types of announcement have a price impact, with review for downgrade and downgrade having the largest. Daniels and Jensen (2005) find a significant market reaction to rating downgrades.

We then study the price effects of announcements subsequent to the onset of the ratings crisis, from July 11, 2007 to December 14, 2009. Whilst there are very few positive announcements in this

\footnotetext{
${ }^{8}$ Holthausen and Leftwich (1986) find that downgrades are associated with negative abnormal stock returns but that upgrades are not. Goh and Ederington (1993) find significant negative abnormal stock returns for downgrades due to earnings deterioration and positive abnormal returns for those due to increases in leverage. Hand, Holhausen and Leftwich (1992) find significant negative stock and bond returns for downgrades and downgrade reviews but no abnormal returns around upgrades. Steiner and Heinke (2001) find significant negative abnormal bond returns around downgrades and downgrade reviews.
} 
period, generally our prior conclusions hold well. Firstly, we find that downgrade reviews continue to invoke the largest announcement day price response. Secondly, there are increases in CDS prices a week in advance of downgrade reviews, the magnitude of which are consistent with the precrisis sample. Thirdly, there is no post-announcement day price movement across announcement types. However, our striking result is a large decrease in market reaction to reviews and rating changes. For downgrade reviews, mean announcement day CDS responses have approximately halved, decreasing from $10.1 \%$ to $5.1 \%$. Similarly, for downgrades they have decreased from $3.3 \%$ to $1.2 \%$. These findings are supportive of the idea that the informational effects of rating announcements were much greater before the rating crisis.

We endeavor to ensure that the reduced price impact of ratings announcements is not driven by inhomogeneity in the samples. Our analysis demonstrates that the distributions of rating level at the time of announcements, the magnitude of rating changes and issuer coverage compare well between these periods, particularly for negative rating announcements. Through the usage of multivariate cross-sectional regressions we also ensure that decreases in announcement day effects are robust to rating characteristics that can alter their informational effects or relate to the effects of costs that firms can incur due to rating changes on their CDS prices. In fact, having conditioned on such variables, we find that the decrease in market response to downgrade reviews and actual downgrades is larger than our univariate event-study results imply. We find that, since the crisis, for the average firm, downgrades reviews invoke an announcement day price response that is $6.7 \%$ lower and actual downgrades invoke a price response that is $2.6 \%$ lower. Therefore, the easiest criticism of our results is that they could simply be coincidental; our rating crisis sample covers the most severe economic downturn in more than half a century which may confound our findings. Yet the cross-sectional evidence we provide, helps attribute the decrease in market reaction to the rating crisis rather than the economic recession. 
This study contributes to the literature in two ways. Firstly, it has revealed an important consequence of the credit rating crisis; it has had a marked effect on Moody's role in the price formation process of corporate credit risk. Secondly, we add to the empirical literature on the relationships between credit ratings and the CDS market. The remainder of this paper is organized as follows. Section II describes our CDS and rating announcement data set. Section III explains the event study methodology and statistical framework we employ. Section IV presents an analysis of the impact of rating announcements on the CDS market prior to, and subsequent to, the onset of the rating crisis. Section $\mathrm{V}$ conducts a multivariate cross-sectional analysis and Section VI concludes.

\section{The Data Set and Descriptive Statistics}

Our data set consists of end-of-day composite mid-market CDS spreads collected from Thomson Reuters Datastream, issuer-level estimated senior unsecured historical rating actions by Moody's, obtained from their Default and Recovery Database ${ }^{9}$ (DRD) and Global Industry Classification Standard (GICS) codes obtained from COMPUSTAT.

\section{A. The CDS Data}

A CDS buyer pays a quarterly premium to the protection seller and receives a settlement equal to the difference between the par and market value of the underlying bond should a default event occur. CDS spreads offer both conceptual and empirical advantages over bond spreads in the analysis of the informational content of bond rating announcements. For instance, CDSs are traded on standardized terms and less affected by differences in covenants and contractual arrangements across obligors than bonds. Also, yield spreads on corporate bonds are affected by the choice of

\footnotetext{
${ }^{9}$ The DRD contains data for 40,000 global corporate and sovereign entities and more than 417,000 individual debt securities, derived from Moody's own proprietary database of issuer, default, and recovery information.
} 
risk-free benchmark yield (Houweling and Vorst (2005)), differential tax treatments (Elton, Gruber, Agrawal and Mann (2001)) and liquidity (Longstaff, Mithal and Neis (2005)) between corporate and treasury bonds. Finally, CDS are generally perceived as a timelier measure of credit risk, as suggested by Blanco, Brennan and Marsh (2005) among others.

Like previous studies in the CDS literature, we focus on five-year quotes which are the benchmark maturity. The CDS data set is provided by CMA DataVision ${ }^{T M}$ and originally sourced from 30 buy-side firms including investment banks, hedge funds and asset managers. According to CMA, contributed quotes are validated, filtered and aggregated using proprietary software. For the publication of prices at $5 \mathrm{pm}$ Eastern Standard Time, a minimum of three consortium members seeing quotes from three distinct sell-side sources must contribute. When there are insufficient observed values to build an entire term structure, CMA fits a proprietary term structure model to the available data to generate the rest of the curve ${ }^{10}$. The raw CDS data set covers the period February 2, 2004 to January 5, 2010 giving 1547 daily observations on 298 U.S. based continually active corporate issuers. All premia are expressed as an annualized spread in basis points on U.S. dollardenominated notional amounts and all reference obligations are senior unsecured debt. Firms are classified using the Global Industry Classifications Standard (GICS) which is an eight-digit, fourtiered, hierarchical classification system. It currently consists of 10 sectors, 24 industry groups, 67 industries and 147 sub-industries. We make use of the two-digit sector level in this study.

\section{B. Rating Announcements and Selection Criteria}

We use Moody's historical issuer-level estimated senior unsecured ratings. In short, a firm's estimated senior rating is set equal to its actual senior unsecured debt rating, or if there is none by

\footnotetext{
${ }^{10}$ We retain CMA's 'derived' prices in our data set. As further controls of data quality, we impose restrictions that, for a given firm, limit the maximum number of consecutive trading days of zero spread change to 20 and the ratio of derived prices to $50 \%$. In our final sample of 205 issuers, the mean (median) percentage of derived to total values is $16 \%(13 \%)$.
} 
implying it on the basis of rated subordinated or secured debt. We concentrate on announcements by Moody's because the existing literature has shown that the various agencies' ratings are related and substitutes for one another ${ }^{11}$. Therefore using announcements by Standard and Poor's in addition could potentially capture more rating events but would also lead to the double counting of many events ${ }^{12}$. In total, 249 issuers in the raw CDS data set are covered by the DRD.

In addition to announcements pertaining to rating changes, which represent a fundamental change in an issuer's long-term creditworthiness, Moody's make two other types of announcement; reviews and outlook reports. Reviews represent a statement that agency analysts are actively reviewing the rating of a firm, either for an upgrade or downgrade in rating. Outlook reports represent agency analysts' forecasts of the medium-term direction of a firm's rating, usually over an 18-month period, and fall into three categories; predicted to improve, predicted to decline and no change expected. Reviews represent a stronger indication of future rating actions than outlooks and agencies typically conclude the review within 90 days ${ }^{13}$.

When analyzing the informational content of rating announcements, contamination must be controlled for so as not to bias inference regarding specific announcement types. We impose fairly stringent filters ${ }^{14}$ to our data compared to previous studies, largely facilitated by its increased span and coverage, but have carefully considered and adjusted our selection rules so as not to impede the representativeness of our final sample. For a given issuer, contamination can arise in the form of closely preceding same-type announcements and or different-type announcements as well as con-

\footnotetext{
${ }^{11}$ For instance Steiner and Heinke (2001) demonstrate that excess bond returns associated with rating actions by Moody's and S\&P are mean difference insignificant.

${ }^{12}$ With regards to Fitch, Norden and Weber (2004) have shown that their announcements did not affect the CDS market in their sample period. Norden (2008) has sought to clarify this in terms of Fitch releasing rating actions relatively late compared to other rating agencies.

${ }^{13}$ However, an issuer does not need to be on review to undergo a rating change; sometimes agencies change ratings without forewarning. Similarly a review does not necessarily guarantee a rating change; issuers can mitigate ratings changes whilst on review by either taking appropriate actions or providing sufficient new information that address the agencies' concerns.

${ }^{14}$ We impose two initial filters to our rating sample. Firstly, we exclude firms whose rating has been withdrawn. Secondly, if an announcement occurred on a day where the CDS spread is 'derived' we exclude the announcement.
} 
temporaneous different-type announcements. We do not consider cross-agency contamination in this study. Given a particular announcement, we control for same-type contamination by removing any subsequent, similar announcement that occurred within 21 trading days ${ }^{15}$. The most problematic source of different-type contamination results from the fact that rating changes are typically preceded by a review. Therefore, we require that matched reviews and ratings changes not be less than 21 days apart. If they are, we eliminate both. We remove other instances of different-type event contamination by removing any announcement that is preceded by another within 21 days. Contemporaneous contamination is typically when, in addition to a rating change, Moody's change the issuer's outlook or place the issuer on review for a further rating change. We exclude all such instances.

\section{Descriptive Statistics}

The sample summaries presented in this section aim to demonstrate that our filtering methodologies should not unduly affect the representativeness of the final sample or bias that of either sub-period. They should also alleviate concerns that differential CDS price responses to ratings announcements before and after the rating crisis are driven by inhomogeneity in announcement samples.

Panel A of Table I provides a summary of the announcement sample by issuer coverage, type, before and after our selection criteria are imposed, and split by period of interest; before and after the rating crisis. Appendix $\mathrm{A}$ lists the issuers and their distribution across GICS economic sectors: Energy (17), Materials (23), Industrials (22), Consumer Discretionary (48), Consumer Staples (19), Health Care (19), Financials (28), IT (12), Telecommunication Services (3) and Utilities (14). The initial sample consists of 1110 rating announcements on 216 issuers over the period

\footnotetext{
${ }^{15}$ We set our event window to 56 trading days, so the maximum overlap of same-type announcements in event time is 35 days. Less than $10 \%$ of announcements are subject to any overlap. Such contamination is confined to the first two sub-divisions of the event window and therefore has no impact on our conclusions.
} 
September 14, 2004 to December 14, 2009 ${ }^{16}$. The final sample retains 542 announcements (49\%) relating to 205 issuers (95\%). Across announcement types, our selection rules give the largest reduction to the number of ratings downgrades where approximately $30 \%$ of the initial sample is retained, mostly due to contemporaneous contamination by negative outlooks and downgrade reviews. In line with previous studies, there are roughly twice as many negative announcements (355) as positive announcements (187) in our final sample. However there are very few positive announcements in the post-crisis period (48), whereas positive and negative announcements are more evenly distributed in the pre-crisis period. Panel B of Table I gives the mean resolution time and percentage success rates for downgrade and upgrade reviews in the initial sample. We find the mean resolution time for downgrade reviews is $\mathbf{5 7 . 3}$ days and that of upgrade reviews is 67.9 days, consistent with other authors. We calculate the success rate of reviews that end in a rating change in the implied direction to be $69.1 \%$ for downgrade reviews and $78 \%$ for upgrade reviews, consistent with Moody's own calculations (See Moody's (2002)).

Panel A of Table [I] presents the distribution of issuers' ratings at the time of rating review in the final sample, again split by period of interest. It reveals that the distributions of issuer rating at downgrade review are very similar before and after the rating crisis, although there are more instances in the post-crisis period; 61 before and 89 after. There are very few upgrade reviews in the post-crisis period and they are concentrated in the investment-grade category, with only three such announcements on high-yield rated issuers. By mapping Moody's ratings onto a numerical 21 grade scale ( $\mathrm{Aaa}=1$ to $\mathrm{C}=21$ ), Panel $\mathrm{B}$ of Table $\Pi$ demonstrates that the sample mean rating at the time of either type of review is Baa3 before July 10, 2007 and Baa2 afterwards; statistically indifferent in both cases.

Finally, Panel A of Table III describes the distribution of rating changes across the periods. There are more upgrades than downgrades in the pre-crisis period, more downgrades in the crisis

\footnotetext{
${ }^{16}$ This period is defined by the requirement of our methodology that ratings announcements need complete timeseries information for the estimation and event windows.
} 
period compared with the pre-crisis period and very few upgrades in the post-crisis period. Approximately $80 \%$ of rating changes are by one grade and nearly all are by three or less. Between the periods, the distribution of rating changes again compares well for both upgrades and downgrades. Panel B of Table III demonstrates that the magnitude of mean rating change is statistically indifferent between the pre- and post-crisis periods ${ }^{17}$.

\section{Event Study Methodology}

The purpose of this event study is to determine abnormal CDS performance attributable to rating announcements; that is the ex post performance of spreads around an announcement relative to the expected performance had no announcement occurred. The three key considerations of our methodological approach are the metric of abnormal performance, the length of the period around the announcement in which to study it, and the statistical testing procedure. We elaborate on each separately below.

\section{A. Estimation and Event Windows}

Using the notation of Campbell, Lo and MacKinlay (1997), CDS spreads are indexed in event time, $\tau$, where $\tau=0$ is the rating announcement date, $\tau=T_{0}+1$ to $\tau=T_{1}$ represents the estimation window and $\tau=T_{1}+1$ to $\tau=T_{2}$ represents the event window. We set the estimation window, $L_{1}=T_{1}-T_{0}$, equal to 120 trading days (six calendar months) and the event window, $L_{2}=T_{2}-T_{1}$, equal to 56 trading days (approx. three calendar months). The event window begins 40 trading days before the announcement, ends 15 days after it, and is divided into $k=6$ subintervals: [$40,-21],[-20,-6],[-5,-1],[0],[1,5],[6,15]$. These correspond to a period of one calendar month

\footnotetext{
${ }^{17}$ Jorion, Liu and Shi (2005) also find the magnitude of rating changes to be stable across time and our estimates of mean rating changes are consistent with Benmelech and Dlugosz (2009) who utilize a larger sample of Moody's bond ratings from the same database.
} 
ending one month before the announcement, a period of three weeks ending a week before the announcement, the week preceding the announcement, the announcement day, the week following the announcement and a two-week period beginning one week after the announcement.

\section{B. Market Model Abnormal Returns}

The studies of Hull et al. (2004) and Norden and Weber (2004) consider CDS spread changes in their analysis because spread changes are more readily related to bond returns. However, when examining spread changes, issuers trading at higher spreads (lower ratings) will exhibit more volatile spreads than issuers trading at lower spreads. In order to deal with the statistical issues that arise from differences in spread levels across issuers, they adjust spread changes by an index spread calculated as the mean of firms with an equivalent whole letter rating to that of the issuer at the time of the event ${ }^{18}$. In this paper we examine log-differences in CDS spreads to alleviate problems associated with changes in spread levels. We then use a market model in conjunction with a market-wide median spread index return ${ }^{19}$, which we believe forms a better benchmark for the conditioning information set of normal performance across all issuers. This is in line with the recent empirical findings of Cathcart, El-Jahel and Evans (2010) and Berndt and Obreja (2010), who demonstrate that a single pervasive component to credit is common to all issuers, regardless of rating category and industry, and statistically analogous to a market factor in equity returns. This framework has the added benefit of allowing the usage of a wider range of robust statistical tests, as highlighted in

\footnotetext{
${ }^{18} \mathrm{~A}$ similar approach is taken by Jorion and Zhang (2007).

${ }^{19}$ We utilize the median instead of the mean given that the post-crisis sample period contains some extreme outliers as thus provides a more robust measure of central tendency. Our main findings are robust to choices pertaining to this specification.
} 
the event study literature (See Binder (1998)). We will refer to log-differences in CDS spreads as $\mathrm{CDS}$ returns ${ }^{20}$ for this analysis:

$$
R_{i, \tau}=\log \left(\frac{S_{i, \tau}}{S_{i, \tau-1}}\right)=\alpha_{i}+\beta_{i} R_{m, \tau}+\varepsilon_{i, \tau}
$$

where $S_{i, \tau}$ is the spread level for security $i$, in event time $\tau . R_{m, \tau}=\log \left(\frac{S_{m, \tau}}{S_{m, \tau-1}}\right)$ is the market index return based on the median spread index $S_{m, \tau}$ of the 249 firms for which we have both CDS and ratings data. $\alpha_{i}$ and $\beta_{i}$ are the parameters to be estimated over the six-month estimation window. $\varepsilon_{i, \tau}$ is the disturbance term with $E\left[\varepsilon_{i, \tau}\right]=0$ and $\operatorname{Var}\left[\varepsilon_{i, \tau}\right]=\sigma_{\varepsilon_{i}}^{2}$. We express this as the regression system:

$$
\mathbf{R}_{\mathbf{i}}=\mathbf{X}_{\mathbf{i}} \theta_{\mathbf{i}}+\varepsilon_{\mathbf{i}}
$$

where $\mathbf{R}_{\mathbf{i}}=\left[\mathbf{R}_{\mathbf{i}, T_{0}+1} \ldots R_{\mathbf{i}, T_{1}}\right]^{\prime}$ is a vector of estimation window CDS returns, $\mathbf{X}_{\mathbf{i}}=\left[\mathbf{1} \mathbf{R}_{\mathbf{m}}\right]$ is a matrix with a vector of ones in the first column and the vector of market index return observations $\mathbf{R}_{\mathbf{m}}=\left[\mathrm{R}_{\mathrm{m}, \mathrm{T}_{0}+1} \ldots \mathrm{R}_{\mathrm{m}, \mathrm{T}_{1}}\right]^{\prime}$ in the second column, and $\theta_{\mathbf{i}}=\left[\alpha_{\mathrm{i}} \beta_{\mathrm{i}}\right]^{\prime}$ is the parameter vector. Given the market model parameter estimates, we analyze the sample vector of abnormal CDS returns, $\widehat{\mathbf{A R}}_{\mathbf{i}}^{*}$, for security $i$ over the event window:

$$
\widehat{\mathbf{A R}}_{\mathbf{i}}^{*}=\mathbf{R}_{\mathbf{i}}^{*}-\mathbf{X}_{\mathbf{i}}^{*} \hat{\theta}_{\mathbf{i}}
$$

where $\mathbf{R}_{\mathbf{i}}^{*}=\left[\mathrm{R}_{\mathrm{i}, \mathrm{T}_{1}+1} \ldots \mathrm{R}_{\mathbf{i}, \mathrm{T}_{2}}\right]^{\prime}$ is the vector of event window CDS returns, $\mathbf{X}_{\mathbf{i}}^{*}=\left[\mathbf{1} \mathbf{R}_{\mathbf{m}}^{*}\right]$ is matrix with a vector of ones in the first column and the vector of event window market index return observations in the second column and $\hat{\theta}_{\mathbf{i}}$ is the parameter vector estimate.

\footnotetext{
${ }^{20}$ This definition does not correspond to the dollar return on a CDS position given a change in spread, which requires the use of a pricing model to ascertain given newly-issued at-market CDS data.
} 


\section{Test Statistics}

To test our hypothesis about the informational content of rating announcements our interest focuses on mean CDS price effects. Our two sample periods exhibit different volatility characteristics as the second covers the global financial crisis. We therefore pay particular attention to variance considerations in our statistical framework. We utilize the $J_{1}$ statistic of Campbell, Lo and MacKinlay (1997), the standardized cross-sectional test statistic of Boehmer, Musumeci and Poulsen (1991) (BMP) and a non-parametric bootstrapped cross-sectional test statistic (BST). We test that, for a given type of rating announcement, cumulative mean abnormal returns or mean standardized cumulative abnormal returns in any event window subinterval are significantly non-zero. See Appendix $B$ for the technical details of the statistics.

\section{The Impact of Rating Announcements on the CDS Market}

\section{A. Pre-Rating Crisis}

Figure 1 plots cumulative mean abnormal CDS returns, across the entire event window, for all six types of rating announcement in the pre-crisis period, September 14, 2004 to July 10, 2007. Table IV presents the corresponding data and results of the three tests on the six sub-divisions of the event window. We observe from Table IV that the test statistics generally agree on non-zero returns. For the analysis, we refer mainly to Panel A, which presents cumulative mean abnormal returns, as their economic interpretation is clearer.

We find no evidence of announcement anticipation in the form of significant movements in abnormal CDS returns until within one calendar week of the announcement. No abnormal performance is detected in the $[-40,-21]$ or $[-20,-6]$ windows for any announcement type. In the $[-5,-1]$ interval, downgrade reviews exhibit a $4.7 \%$ abnormal spread increase, significant at the $5 \%$ level 
in the BMP test and the $1 \%$ level in the $J_{1}$ and BST tests. We find no abnormal performance before downgrade, outlook negative, upgrade review, upgrade and outlook positive in this period.

In terms of announcement day effects in the [0] interval, all announcements apart from positive outlook have a statistically significant impact on spreads. The largest is the average increase of $10.1 \%$ in abnormal CDS spreads at downgrade review; a well-documented relative result and in consensus with previous studies. For upgrades reviews, the mean announcement day decrease is $6.1 \%$, and for downgrades there is an average increase of $3.3 \%$. These results are $1 \%$ significant in all tests. For the remaining announcement types, the results are less conclusive but the signs are consistent with our expectations. The $1.5 \%$ increase for negative outlooks is $5 \%$ significant in the $J_{1}$ test alone. The $1.5 \%$ decrease at rating upgrade is at least $10 \%$ significant in all tests. The $0.19 \%$ decrease at positive outlook is not found to be significant.

With regards to the post-announcement intervals, [1,5] and [6,15], we find weak evidence of significant changes in spreads after downgrade review and outlook negative. The BMP and BST tests find the increase in spreads of $2.5 \%$ the week after downgrade reviews $10 \%$ significant. Similarly, the BMP test finds the mean increase in spreads of $1.8 \%$ the week after negative outlooks $10 \%$ significant. We investigated this result further as it would suggest an informational inefficiency in the CDS market. By looking at the cross-section of $[0,1]$ abnormal CDS returns, we find that a small number of significant returns occur on day +1 . This is result of data synchronicity; our Moody's rating actions are not time-stamped and so may have occurred after the 5pm publication of the CDS data. Extending the announcement day interval to $[0,1]$ removes this result ${ }^{21}$ and allows us to conclude that CDS spreads fully adjust to the information in rating announcements by day +1 . This is indicative evidence in favor of the CDS market being informationally efficient

\footnotetext{
${ }^{21}$ In unreported results, we repeated the entire analysis of this paper by extending the announcement day interval to $[0,1]$. Outlook positive becomes significant using this specification of announcement day. This extension comes at a cost; most of the large spread responses to announcements do occur at day zero and by smoothing announcement day effects across a two-day period there is a slight decrease in significance in our cross-sectional analysis. However, our main findings remain unchanged and robust to this specification.
} 
and in agreement with previous studies. Finally, the well established asymmetry of the impact of positive and negative announcements can be seen in Figure 1. However it must be noted that our results relate the asymmetry to differences in the degree of anticipation and absolute magnitude of announcement day effect, not that positive announcements have no influence on spreads. This is in contrast to the results of Hull et al. (2004) and Norden and Weber (2004). However, both freely concede that a deficiency of positive announcements in their samples hinder strong conclusions.

\section{B. Post-Rating Crisis}

Figure 2 plots cumulative mean abnormal CDS returns between July 11, 2007 and December 14, 2009 and Table $\mathrm{V}$ presents the corresponding data and test results. We find no evidence of statistically significant anticipation of announcements before the $[-5,-1]$ interval, in agreement with the results of pre-crisis data set. Downgrade reviews and negative outlooks exhibit significant abnormal performance in the preceding week; the increase in mean abnormal CDS returns are $5.5 \%$ and $3.1 \%$ respectively. These results are significant at the $1 \%$ level in all tests for downgrade reviews. The $J_{1}$ test assigns $5 \%$ significance to the result for negative outlooks and the BST test assigns $10 \%$ significance. Also consistent with the pre-crisis sample, there is no anticipation of downgrades or positive events. However, the signs on cumulative mean abnormal returns are typically in the expected direction.

As for announcement day effects, downgrade reviews continue to invoke the largest spread response with a mean abnormal return of $5.1 \%$ in this period, $1 \%$ significant in all tests. For downgrades, it is $1.2 \%$ and $10 \%$ significant in all tests. For negative outlooks $1.4 \%$, which is $5 \%$ significant in the $J_{1}$ and BMP tests. With regards to positive announcements, sample deficiency clearly hampers our analysis and interpretation of the test results so we refrain from drawing strong conclusions in this period. Nonetheless, we observe that the spread response to upgrade reviews and upgrades are $-1.2 \%$ and $0.1 \%$ respectively and statisitically insignificant. Finally, consistent 
with the pre-crisis period, we find no evidence of abnormal performance in the post-announcement intervals across all events once we adjust for the day +1 effect.

In sum, our findings suggest that negative announcements by Moody's influenced the CDS market prior to, and subsequent to, the onset of the rating crisis. By comparing the pre- and postcrisis results (Tables $\mathrm{IV} \& \mathrm{~V}$, we observe a large decrease in announcement day price effects. For downgrade reviews it has decreased from $10.1 \%$ to $5.1 \%$, for downgrades it has decreased from $3.3 \%$ to $1.2 \%$ and for upgrade reviews it has decreased in absolute terms from $-6.1 \%$ to $-1.2 \%$. Whilst we have found no evidence of anticipation effects for rating downgrades or positive announcements, the pre-announcement anticipation of downgrade reviews in the $[-5,-1]$ interval has remained consistent, increasing slightly from $4.7 \%$ to $5.5 \%$. That of outlook negative has increased from $1.0 \%$ to $3.1 \%$. We therefore test the hypotheses of differences in cumulative mean abnormal returns and mean standardized cumulative abnormal returns before and after the crisis, in both the $[-5,-1]$ and $[0]$ intervals, across all announcement types. The results are reported in Table VI. Panel A demonstrates that we find no evidence of statistically significant differences in mean anticipation effects for any announcement type. Panel B shows that the drop in announcement day return at downgrade reviews, downgrades and upgrade reviews is statistically significant in both specifications of abnormal performance.

\section{Interpretation of Results}

The decrease in market reaction to Moody's announcements since the onset of the rating crisis is unlikely related to a change in the informational advantage of Moody's or a change in bond rating methodology that could have reduced the informational content of ratings. We are unaware of any changes to either during the sample period ${ }^{22}$. Therefore, our empirical evidence might support

\footnotetext{
${ }^{22}$ In contrast, Moody's structured product rating methodologies have been subject to various changes. See Griffin and Tang (2010).
} 
the hypothesis that market participants perceive that the incremental information conveyed by such announcements, over and above that already known and priced in spreads, has decreased. However, alternative explanations must also be considered. Firstly, one must take into account announcement characteristics that can influence information effects. Although we have demonstrated that the distribution of rating levels and changes, as well as issuer coverage, are well matched between our sample periods, we will explicitly control for such characteristics in a multivariate setting.

Secondly, although ratings are intended as a channel by which to improve the flow of information in debt markets, in the limit that they contain no new information about a firm's credit risk, rating changes can still impact prices because downgrades and upgrades impose real costs on firms. Many regulations reference ratings ${ }^{23}$ and some institutional investors are restricted from holding high-yield debt. As explained by Kisgen (2006), access to the commercial paper market is rating dependent and ratings are further referenced in many financial contracts, both public and private. For instance, bond covenants and loan agreements can contain ratings triggers that result in rate changes or even forced repurchases (See Bhanot and Mello (2006)). Kisgen and Strahan (2009) show that ratings-based regulations affect a firm's cost of debt capital. If costs play an important role in CDS responses to rating actions, then the decrease in market reaction we observe would imply that rating actions are less costly to firms in the post-crisis era. Again, we are unaware of any change in the regulatory framework that relies on ratings during our sample period, hence this line of reasoning is difficult to justify. Also, given the homogeneity of our samples, the effects of discrete costs associated with different rating levels should be comparable. Nonetheless, we will provide some further tests of the influence of rating related costs on the magnitude of CDS responses to rating actions.

Finally, the rating crisis period includes the most severe economic downturn in more than half a century. In trying to establish a link between a decrease in market reaction to rating announcements

\footnotetext{
${ }^{23}$ The Joint Forum (2009) details member authorities' usage of credit ratings in legislation, regulations and supervisory policies.
} 
and the rating crisis, our results could simply be coincidental. One could argue that the onset of the global recession may have contributed to the reduction in the price effects of announcements. For instance, in a period were there is far more negative news from Moody's, combined with pessimism amongst market participants, such announcements may be expected and therefore have less of an impact. Using the data in Table $\mathbb{I}$ we calculate that in the pre-crisis period, on average a negative announcement was made every 441 firm-days. In the post-crisis period, on average a negative announcement was made every 214 firm-days; a doubling in frequency. If so, the question would be why do we observe a decrease in the price effects of upgrade reviews, when the frequency of positive announcements is much lower. We calculate from that on average a positive announcement was made every 523 firm-days in the pre-crisis period and 1276 firm-days in the post-crisis period; more than a halving in frequency. Alternatively, one could argue that during an economic downturn, investors overreact to downgrades whereas upgrades are perceived more favorably. If this alternative reasoning is literally true, then we may be underestimating the impact of the rating crisis on CDS price responses to rating announcements. Because the influence of the economic cycle is ambiguous ex ante, we also endeavor to ensure that it does not unduely bias our results in the following section.

\section{Multivariate Cross-sectional Analysis of Announcement Day Performance}

Our aim in this final section is to ensure that the observed decrease in CDS responses to rating announcements supports our hypothesis that the rating crisis has altered the information effects of corporate credit ratings against alternative explanations. In order to do so, we first perform a cross-sectional analysis of announcement-day abnormal returns, from both the pre- and post-crisis

periods simultaneously, on variables that potentially influence information effects or relate to the 
costs associated with rating changes. We then perform a cross-sectional analysis of announcementday abnormal returns from the post-crisis period to ensure that the economic recession does not unduely influence our findings. We only consider downgrade reviews and actual downgrades in this analysis due to the sample limitations of positive events. We concentrate on standardized cumulative abnormal returns as our cross-section covers the global financial crisis; our data exhibits substantial cross-sectional variation in the volatility of abnormal CDS returns and some of our variables are correlated with volatility.

\section{A. Information and Cost Considerations}

\section{A.1. Regression Specification}

For downgrade reviews we estimate the regression:

$$
\widehat{S C A R}_{i, 4}^{R R D}=\gamma_{0}+\gamma_{1} R C D_{i}+\gamma_{2} I G D_{i}+\gamma_{3} P N E D_{i}+\gamma_{4} B D_{i}+\eta_{i}
$$

Where $\widehat{S C A R}_{i, 4}^{R R D}$ is the announcement day standardized cumulative abnormal return for downgrade review announcement $i$ as defined in Equation (18), Appendix B. The Rating Crisis Dummy (RCD) is zero if the observation is from the pre-crisis period, September 14, 2004 to July 10, 2007, and one if it is from the post-crisis period, July 11, 2007 to December 14, 2009. The Investment Grade Dummy (IGD) is one if the firm is rated above Baa3 and zero otherwise. The Previous Negative Events Dummy (PNED) is one if the period spanning the estimation and pre-announcement event window (160 days, eight calendar months) contains any other negative announcements. We use the initial ratings sample to determine preceding announcements on the issuer. The Boundary Dummy 
(BD) is one if the firm is rated Baa3 at downgrade review and zero otherwise. For downgrades we estimate the regression:

$$
\widehat{S C A R}_{i, 4}^{R D}=\gamma_{0}+\gamma_{1} R C D_{i}+\gamma_{2} I G D_{i}+\gamma_{3} P N E D_{i}+\gamma_{4} N C D_{i}+\gamma_{5} C B D_{i}+\eta_{i}
$$

Where $\widehat{S C A R}_{i, 4}^{R D}$ is the announcement day standardized cumulative abnormal return for rating downgrade announcement $\mathrm{i}$ as defined in Equation (18), Appendix B. In addition to the variables defined previously, the Notches Changed Dummy (NCD) equals one if the firm's rating was revised more than one notch and zero if it was equal to one notch and Crosses Boundary Dummy (CBD) equals one if the rating revision reclassifies the firm as high-yield.

In both regressions, interest centers on the coefficients of $\mathrm{RCD}$, which measures the impact of the rating crisis on the intercept. If bond rating announcements have become less informative, then its coefficients should be negative in both specifications. We condition on three other variables that may potentially influence information effects. Firstly, we include IGD to examine whether price responses to negative announcements for investment-grade issuers differ from those of highyield issuers, on average. Ceteris paribus, we might expect a negative coefficient if the quantity of processed credit information is positively correlated with rating, i.e. rating announcements have a higher information effect for lower credit quality firms. Secondly, we include PNED because longer periods between consecutive negative announcements might suggest that each announcement generates additional information to the CDS market. Conversely, longer periods between announcements might suggest that the announcements are less timely. Therefore ex ante, the sign on this coefficient is ambigious ${ }^{24}$. Thirdly, the magnitude of the rating revision is captured by NCD. We expect a positive coefficient on this variable if larger rating changes reveal more information to the market.

\footnotetext{
${ }^{24}$ Previous evidence on this interaction is mixed. Jorion, Liu and Shi (2005) find a significantly positive relationship between announcement frequency and abnormal stock performance, Steiner and Heinke (2001) find no relationship for bonds and Norden and Weber (2004) find a significantly positive relationship for CDS but the opposite for stocks.
} 
We also condition on rating characteristics that control for the influence of rating-related costs on spreads. At the investment-grade boundary, regulations based on credit ratings are most binding and ratings changes from investment-grade to high-yield are the most costly (Kisgen (2006) and Kisgen and Strahan (2009)). We include BD and CBD as no prior study has examined this issue in a cross-sectional analysis of CDS performance ${ }^{25}$. If the costs associated with ratings changes play an important role in the magnitude of CDS responses to rating announcements, we expect to observe positively significant coefficients on these variables. Whilst reviews are not known to be used for regulatory or contractual purposes, given that the success rate of downgrade reviews is approximately $70 \%$ in Table $\mathbb{I}$, if participants expect a subsequent downgrade, then all the relevant information is conveyed by the review. In this case, investors would trade at the review date to avoid further losses from selling coercion at the downgrade date.

For robustness, we also conduct these regressions using Standardized Gross Spread Changes $(S G S C)$ as the dependent variable. This is defined as a securities' announcement-day spread change divided by an estimate of spread change volatility, $\hat{\sigma}_{i}^{\Delta S^{c d s}}$, calculated during the estimation window:

$$
S G S C_{4}=\frac{\Delta S_{i, \tau=0}}{\hat{\sigma}_{i}^{\Delta S}}
$$

Our main result, that is a decrease in market reaction to Moody's reviews and rating changes, is derived using log-differences in spreads in conjunction with a market model. The idea here is to remove the model dependency from our performance metric, whilst allowing comparability, preand post-rating crisis, via the standardization.

\footnotetext{
${ }^{25}$ Previous evidence for other asset classes is mixed. Hand, Holhausen and Leftwich (1992) find no contribution to abnormal bond performance for bonds moving out of investment grade, Steiner and Heinke (2001) find the opposite and Jorion, Liu and Shi (2005) find a contribution to abnormal stock performance.
} 


\section{A.2. Results}

The results of the cross-sectional regressions are presented in Table VII In order to interpret these, we note that the average estimated standard error of cumulative abnormal announcement day returns (Equation (17)), across all instances of downgrade review is $4.43 \%$ and that of rating downgrade is $3.97 \%$.

For downgrade reviews, focussing first on the standardized cumulative abnormal return specification in Panel A of Table VII], the coefficient on the rating crisis dummy (RCD) is significantly negative as expected. This suggests that the mean CDS reaction to downgrade reviews is considerably weaker in the post-crisis period, conditioning on the other variables. Its coefficient implies that the abnormal CDS return for a downgrade review on the average firm drops by $-1.53 \times 4.43 \%$, or $-6.7 \%$, which is $5 \%$ signficant. This is higher than the decrease in mean abnormal CDS return of $-5.0 \%$ that we observed in the univariate event-study setting (Table VI). For downgrades, in Panel B, the rating crisis dummy's coefficient implies that the average abnormal CDS price response decreases by $-0.65 \times 3.97 \%$, or $-2.6 \%$, and is $5 \%$ significant. Again, this is higher than in the univariate setting, where the decrease was observed to be $-2.2 \%$ (Table VI). We note that the regressions using standardized gross spread changes confirm our findings; RCD is 5\% significant in both. These results are strongly supportive of the hypothesis of a reduction in the information effects of rating announcements.

The investment grade dummy (IGD), although not statistically significant, has the expected negative signs in three of the four regressions. The differential in average abnormal CDS reaction of investment-grade issuers to that of high-yield issuers is $-0.55 \times 4.43 \%$, or $-2.4 \%$, at downgrade review and $-0.29 \times 3.97 \%$, or $-1.2 \%$, at rating downgrade. These results demonstrate that our findings are not unduly influenced by differences in the informational effects of announcements pertaining to investment-grade and high-yield issuers. The decrease in price effects that we observe are therefore more likely common to both classifications in support of our hypothesis; if the 
information effects of rating announcements have decreased due to the rating crisis, they should have decreased across the rating spectrum. The previous negative news dummy (PNED) is both highly statistically and economically significant for downgrade reviews in the standardized cumulative abnormal return specification. The negative coefficient of -1.81 implies that at downgrade review on the average firm, there is a differential abnormal CDS return of $8.0 \%$ if no prior negative announcements were made in the preceding eight months. However, this result does not hold in the gross spread change specification. For actual downgrade we find PNED to be insignificant. Given that typically a downgrade is preceded by a review or negative outlook, this result is not surprising. Lastly, the notches changed dummy (NCD) is weakly statistically significant with a coefficient that implies that on average, a rating change of greater than one notch yields a differential abnormal CDS response of $-1.5 \%$. The CDS market does appear to value the size of the rating change ${ }^{26}$.

With regards to the influence of the costs associated with rating changes on spreads, the crosses boundary dummy (CBD) in the rating downgrade regressions carries a positive sign in both specifications, as expected. The coefficient of 0.46 in the standardized cumulative abnormal return specification implies that a rating change which reclassifies a firm as high-yield invokes a differential CDS price response of $1.8 \%$ over those that do not, but is statistically insignificant. The boundary dummy (BD) in the downgrade review regressions, is also not statistically significant and its signs are inconsistent between the two specifications. The differential average abnormal CDS reaction of firms most at risk of being downgraded to high-yield is $-1.6 \%$. Therefore, it is unlikely that the costs associated with ratings changes, or sample differences between them across our two periods, play a major role in mean CDS price effects. To conclude, our finding of a reduction in the CDS market's responses to rating announcements since the onset of the rating crisis is robust to the inclusion of these rating-related characteristics. It is also robust to our abnormal performance specification. We turn our attention now to the influence of the business cycle.

\footnotetext{
${ }^{26}$ This finding is at odds with previous studies. Hand, Holhausen and Leftwich (1992) and Steiner and Heinke (2001) find no reliable evidence that it effects the magnitude of excess bond returns and Norden and Weber (2004) come to a similar conclusion with respect to both abnormal equity returns and CDS spread changes.
} 


\section{B. Business Cycle Considerations}

Disentangling the influence of the business cycle from that of the rating crisis is complicated by the fact that our post-crisis period includes the recent economic recession, widely cited as being the most severe since the first half of the 20th century. According to the National Bureau of Economic Research (NBER), it began in December 2007 and ended in June 2009. One might argue that our rating crisis dummy is therefore correlated with the business cycle and simply picking up other confounding effects unrelated to the rating crisis. We endeavor to alleviate such concerns here.

\section{B.1. Regression Specification}

For downgrade reviews we estimate the regression:

$$
\widehat{S C A R}_{i, 4}^{R R D}=\gamma_{0}+\gamma_{1} N B E R D_{i}+\gamma_{2} I G D_{i}+\gamma_{3} P N E D_{i}+\gamma_{4} B D_{i}+\eta_{i}
$$

For rating downgrades we estimate the regression:

$$
\widehat{S C A R}_{i, 4}^{R D}=\gamma_{0}+\gamma_{1} N B E R D_{i}+\gamma_{2} I G D_{i}+\gamma_{3} P N E D_{i}+\gamma_{4} N C D_{i}+\gamma_{5} C B D_{i}+\eta_{i}
$$

Where $\widehat{S C A R}_{i, 4}^{R R D}$ and $\widehat{S C A R}_{i, 4}^{R D}$ are the announcement day standardized cumulative abnormal return for downgrade review and rating downgrade as defined in Equation (18), Appendix B. In these regressions, we only consider observations from the post-crisis sample period, July 11, 2007 to December 14, 2009. In total there are 89 instances of downgrade review and 50 instances of downgrade, as seen in Table II. We use a National Bureau of Economic Research Dummy (NBERD), which takes a value of one if the observation is from the months spanning December 2007 to June 2009. The other variables are as defined in Section A.1. 
Interest here is focused on the coefficient of NBERD. If the economic downturn plays an important role in the magnitude of mean CDS responses to rating announcements in our post-rating crisis sample, we expect significant coefficients in both regressions although the signs are ambiguous, a priori. Significantly negative coefficients would suggest that our interpretation of the decrease in market response to negative announcements is confounded by the influence of the economic recession. Significantly positive coefficients would suggest that a decrease in information effects due to the rating crisis is to some extent counteracted by the influence of the business cycle. Again, for robustness we repeat these regressions using standardized gross spread changes as defined in Equation (6).

\section{B.2. Results}

Table VIII presents the results of the cross-sectional regressions. The average estimated standard error of cumulative abnormal announcement day returns in the post-crisis period for downgrade review is $4.31 \%$ and that of rating downgrade is $4.14 \%$. In all four regressions the coefficients on NBERD are insignificant. This finding increases our confidence that it was the rating crisis and not the economic recession that was the main factor in the decrease in market reaction to negative rating announcements.

With regards to the control variables, the results are consistent with those of Section A.2. IGD typically carries a negative sign and is statistically insignificant in all regressions. PNED has explanatory power for the magnitude of abnormal CDS response to downgrade reviews but not actual downgrades. NCD is insignificant during this period but continues to carry a negative sign. $\mathrm{BD}$ and $\mathrm{CBD}$ remain insignificant. 


\section{Conclusion}

The credit rating crisis, stemming from the flawed ratings of structured products in the buildup to the global financial crisis, had systemic consequences for financial markets. One of the hitherto unexplored implications of this episode is how it has affected the role of the CRAs in the price formation process of corporate credit risk.

The empirical evidence presented in this paper indicates that the rating crisis altered the information effects of Moody's corporate bond ratings, as captured by the CDS market. We find that the price impact of their rating announcements has diminished significantly since the mass structured products downgrades that began in July 2007. Particularly for downgrade reviews, upgrade reviews and downgrades, which invoked the largest spread responses prior to the crisis. Whether or not these effects are short-lived and transitory remains to be seen given the proposed changes to the credit rating industry under the Dodd-Frank Act.

Having explored various alternative explanations of the decrease in market reaction to Moody's announcements, we are inclined to attribute it to the reputational damage inflicted on the major CRAs following their role in the structured products collapse. This could have transpired into a market-wide loss in confidence in the integrity of the rating scale, the incentives and expertise of Moody's analysts in gathering, processing and assessing price-relevant information about corporate credit risk. In light of our findings, we believe that a prudential policy recommendation is the separation of bond and securitized product rating symbols. In theory bond ratings provide a useful economic function by reducing problems of asymetric information, and in practice have been independently validated through a long history of empirical testing. Maintaining the integrity of the bond rating system is important, particularly if the institutional and regulatory reliance on ratings persists. 


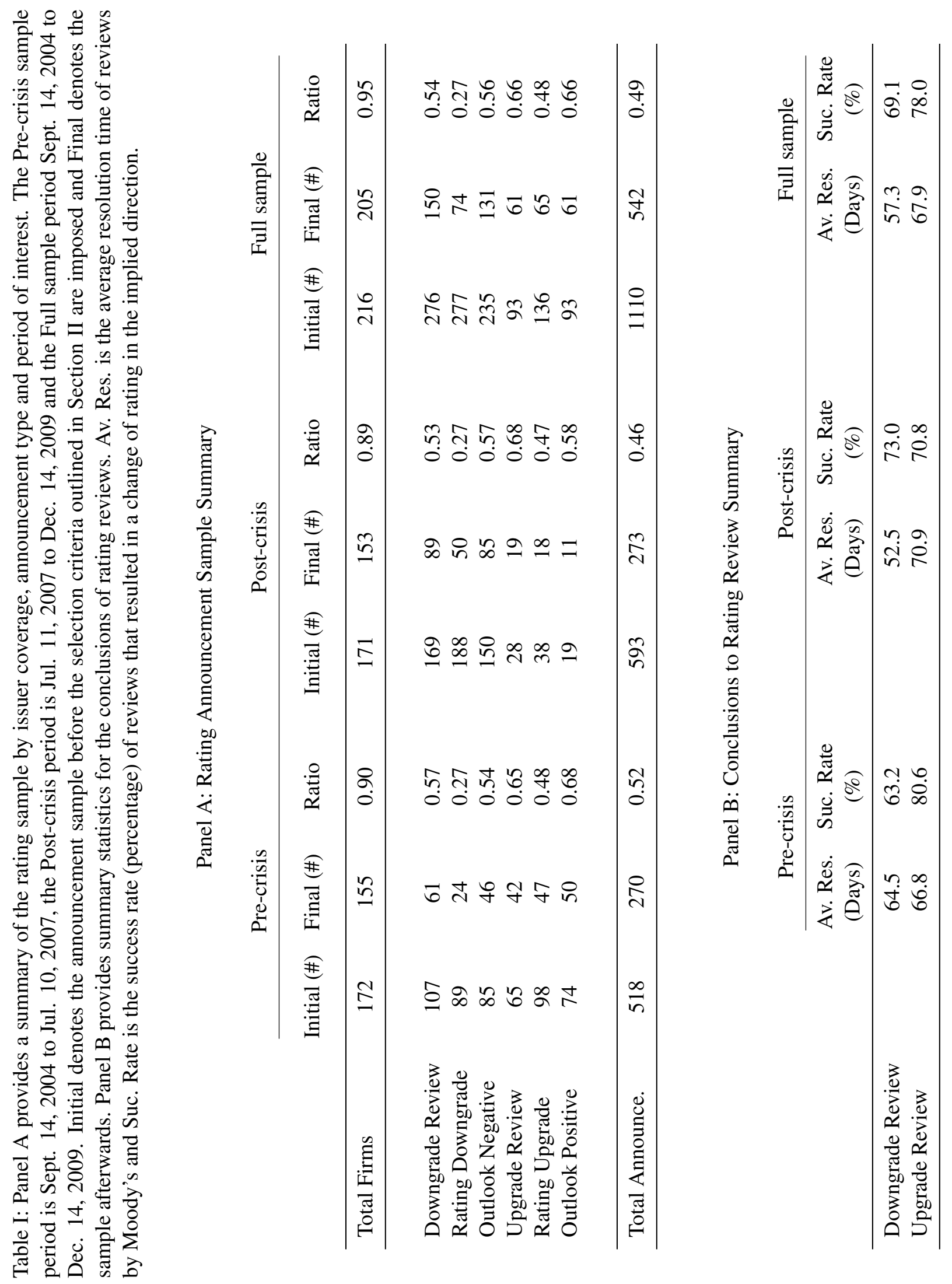


Table II: Panel A provides the distribution of issuers' ratings at the announcement of downgrade review or upgrade review by Moody's. These reviews pertain to the final sample, described in Section II. The Precrisis period is Sept. 14, 2004 to Jul. 10, 2007 and the Post-crisis period is Jul. 11, 2007 to Dec. 14, 2009. Issuers' ratings are split by whole letter rating category, except near the boundary where we consider $\mathrm{Baa} 3$ and Ba1 as distinct given their importance as the investment-grade boundary. Panel B uses a paired difference test to determine whether the mean issuer rating at the time of reviews varies across the periods.

Panel A: Rating Review Sample Comparison

\begin{tabular}{lcccccccc} 
& \multicolumn{3}{c}{ Downgrade Reviews } & \multicolumn{3}{c}{ Upgrade Reviews } \\
\cline { 2 - 10 } & \multicolumn{2}{c}{ Pre-crisis } & \multicolumn{2}{c}{ Post-crisis } & \multicolumn{2}{c}{ Pre-crisis } & \multicolumn{2}{c}{ Post-crisis } \\
\hline Initial Rating & $\#$ & $\%$ & $\#$ & $\%$ & $\#$ & $\%$ & $\#$ & $\%$ \\
\hline Aaa & - & - & 1 & 1.1 & - & - & - & - \\
Aa & 2 & 3.3 & 7 & 7.9 & 1 & 2.4 & - & - \\
A & 12 & 19.7 & 18 & 20.2 & 8 & 19.0 & 5 & 26.3 \\
Baa1/2 & 23 & 37.7 & 28 & 31.5 & 13 & 31.0 & 6 & 31.6 \\
Baa3 & 7 & 11.5 & 10 & 11.2 & 5 & 11.9 & 5 & 26.3 \\
Ba1 & 2 & 3.3 & 5 & 5.6 & 6 & 14.3 & 1 & 5.3 \\
Ba2/3 & 6 & 9.8 & 9 & 10.1 & 4 & 9.5 & 1 & 5.3 \\
B & 8 & 13.1 & 9 & 10.1 & 4 & 9.5 & 1 & 5.3 \\
Caa & 1 & 1.6 & 2 & 2.2 & 1 & 2.4 & - & - \\
Ca/C & - & - & - & - & - & - & - & - \\
Total & 61 & & 89 & & 42 & & 19 & \\
\hline
\end{tabular}

Panel B: Paired Difference Tests

Downgrade Reviews

Upgrade Reviews

\begin{tabular}{|c|c|c|c|c|}
\hline & \\
\hline & Pre-crisis & Post-crisis & Pre-crisis & Post-crisis \\
\hline Av. Rating at Review & Baa3 (9.6) & Baa2 (9.1) & Baa3 (9.8) & $\mathrm{Baa} 2(9.1)$ \\
\hline Difference & \multicolumn{2}{|c|}{-0.49} & \multicolumn{2}{|c|}{-0.68} \\
\hline t-stat & \multicolumn{2}{|c|}{-0.90} & \multicolumn{2}{|c|}{-1.07} \\
\hline
\end{tabular}


Table III: Panel A provides the distribution of rating changes in the final sample as absolute differences in Moody's 21 grade numeric scale. The Pre-crisis period is Sept. 14, 2004 to Jul. 10, 2007 and the Post-crisis period is Jul. 11, 2007 to Dec. 14, 2009. Panel B uses a paired difference test to determine whether the magnitude of mean rating change differs between the periods.

\section{Panel A: Rating Change Sample Comparison}

\begin{tabular}{lcccccccc} 
& \multicolumn{3}{c}{ Rating Downgrades } & \multicolumn{3}{c}{ Rating Upgrades } \\
\cline { 2 - 9 } & \multicolumn{2}{c}{ Pre-crisis } & \multicolumn{2}{c}{ Post-crisis } & \multicolumn{2}{c}{ Pre-crisis } & \multicolumn{2}{c}{ Post-crisis } \\
\hline Change & $\#$ & $\%$ & $\#$ & $\%$ & $\#$ & $\%$ & $\#$ & $\%$ \\
\hline 1 & 19 & 79.1 & 36 & 72.0 & 37 & 78.7 & 15 & 83.3 \\
2 & 4 & 16.7 & 10 & 20.0 & 8 & 17.0 & 2 & 11.1 \\
3 & 1 & 4.2 & 2 & 4.0 & 2 & 4.3 & - & - \\
4 & - & - & - & - & - & - & 1 & 5.6 \\
5 & - & - & 1 & 2.0 & - & - & - & - \\
6 & - & - & - & - & - & - & - & - \\
7 & - & - & 1 & 2.0 & - & - & - & - \\
Total & 24 & & 50 & & 47 & & 18 & - \\
\hline
\end{tabular}

Panel B: Paired Difference Tests

\begin{tabular}{|c|c|c|c|c|}
\hline & \multicolumn{2}{|c|}{ Rating Downgrades } & \multicolumn{2}{|c|}{ Rating Upgrades } \\
\hline & Pre-crisis & Post-crisis & Pre-crisis & Post-crisis \\
\hline Mean Change & -1.25 & -1.48 & 1.26 & 1.28 \\
\hline Difference & \multicolumn{2}{|c|}{-0.23} & \multicolumn{2}{|c|}{0.02} \\
\hline t-stat & \multicolumn{2}{|c|}{-1.21} & \multicolumn{2}{|c|}{0.11} \\
\hline
\end{tabular}


Figure 1: A plot of cumulative mean abnormal CDS returns around the six types of rating announcement by Moody's in the pre-rating crisis period Sep. 14, 2004 to Jul. 10, 2007. Event time 0 represents the calendar date of announcements. The vertical dotted lines are the lower bounds of the event window subdivisions. Numbers in brackets in the legend denote the sample size.

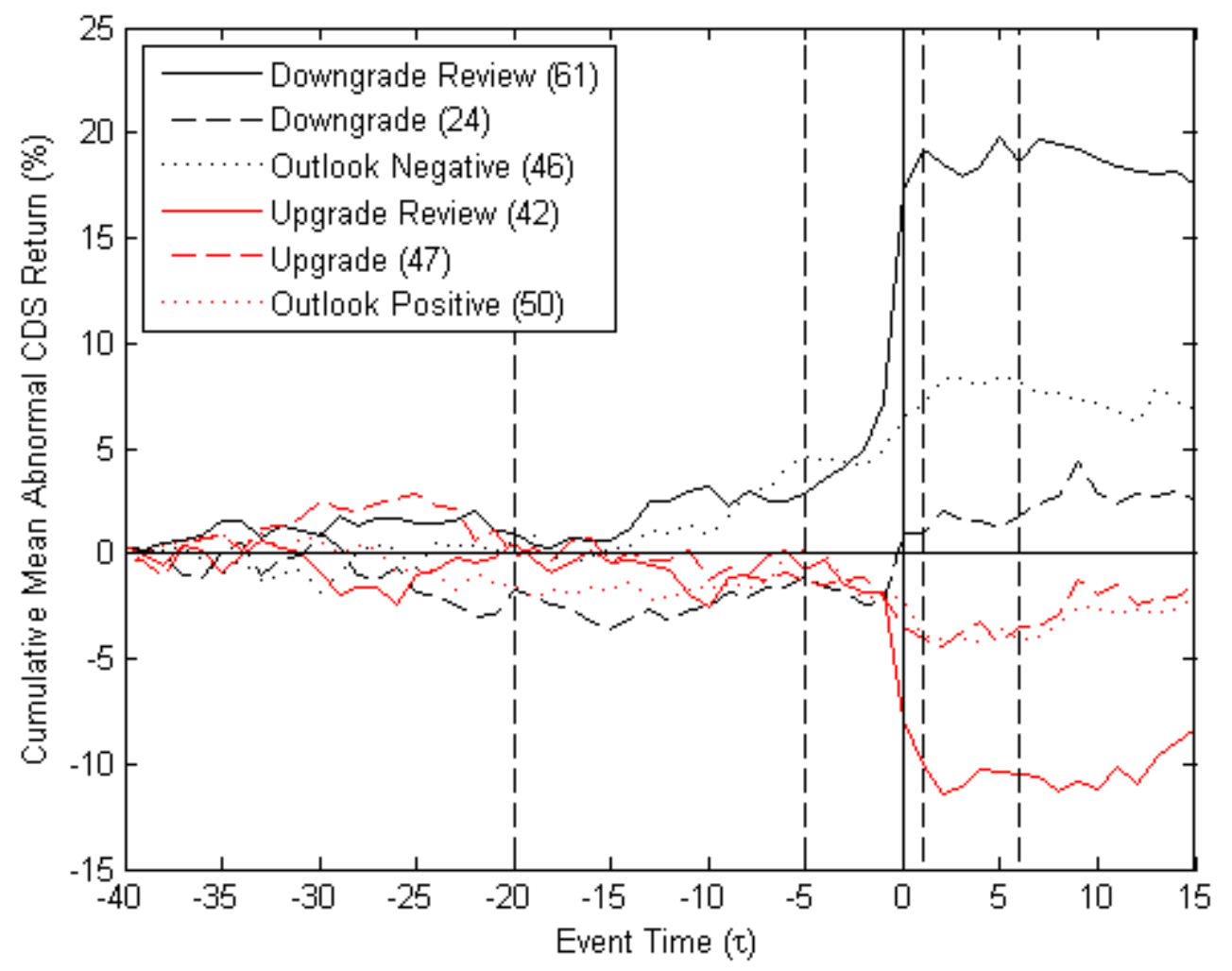


Table IV: Panel A presents cumulative mean abnormal CDS returns during the pre-crisis period, as given by Equation (13) in Appendix B. The results of the $\mathrm{J} 1$ test statistic in Equation (15) are denoted by: $*(10 \%)$, $* *(5 \%)$ and $* * *(1 \%)$. The results of the cross-sectional bootstrap test in Equation (21) are denoted by $\dagger$ using the same convention. Panel B presents the corresponding mean standardized cumulative abnormal CDS returns, during the pre-crisis period, as given by Equation (19). The equivalent results of the BMP test in Equation 20 are denoted by $\%$.

Panel A: Cumulative Mean Abnormal CDS Returns (\%)

Event Window Subdivision

\begin{tabular}{|c|c|c|c|c|c|c|}
\hline Announcement & {$[-40,-21]$} & {$[-20,-6]$} & {$[-5,-1]$} & {$[0]$} & {$[1,5]$} & {$[6,15]$} \\
\hline Downgrade Review & 1.03 & 1.45 & $4.65_{\dagger \dagger \dagger}^{* * *}$ & $10.1_{\dagger \dagger \dagger}^{* * *}$ & $2.53 \dagger$ & -2.22 \\
\hline Rating Downgrade & -2.91 & 1.28 & -0.72 & $3.34_{\dagger \dagger \dagger}^{* * *}$ & 0.22 & 1.42 \\
\hline Outlook Negative & 0.08 & 3.92 & 0.97 & $1.48^{* *}$ & 1.84 & -1.43 \\
\hline Upgrade Review & -0.17 & 0.27 & -1.95 & $-6.06_{\dagger \dagger \dagger}^{* * *}$ & -2.44 & 1.93 \\
\hline Rating Upgrade & 1.04 & -1.92 & -1.13 & $-1.51_{\dagger}^{*}$ & -0.80 & 2.90 \\
\hline Outlook Positive & -1.52 & 1.41 & -1.87 & -0.19 & -1.46 & 1.66 \\
\hline
\end{tabular}

Panel B: Mean Standardized Cumulative Abnormal CDS Returns

Event Window Subdivision

\begin{tabular}{|c|c|c|c|c|c|c|}
\hline Announcement & {$[-40,-21]$} & {$[-20,-6]$} & {$[-5,-1]$} & {$[0]$} & {$[1,5]$} & {$[6,15]$} \\
\hline Downgrade Review & 0.006 & 0.023 & $0.279^{\prime \prime}$ & $3.170^{\prime \prime \prime}$ & $0.166^{\prime}$ & -0.077 \\
\hline Rating Downgrade & -0.033 & 0.053 & 0.015 & $1.000^{\prime \prime \prime}$ & 0.028 & 0.070 \\
\hline Outlook Negative & 0.026 & $0.090^{\prime}$ & 0.081 & 0.457 & $0.121^{\prime}$ & -0.020 \\
\hline Upgrade Review & -0.009 & -0.011 & -0.152 & $-1.760^{\prime \prime \prime}$ & -0.158 & 0.042 \\
\hline Rating Upgrade & 0.029 & -0.025 & -0.069 & $-0.343^{\prime \prime}$ & 0.060 & 0.070 \\
\hline Outlook Positive & -0.007 & 0.037 & -0.100 & -0.061 & -0.060 & 0.070 \\
\hline
\end{tabular}


Figure 2: A plot of cumulative mean abnormal CDS returns around the six types of rating announcement by Moody's in the post-rating crisis period, Jul. 11, 2007 to Dec. 14, 2007. Event time 0 represents the calendar date of announcements. The vertical dotted lines are the lower bounds of the event window subdivisions. Numbers in brackets in the legend denote the sample size.

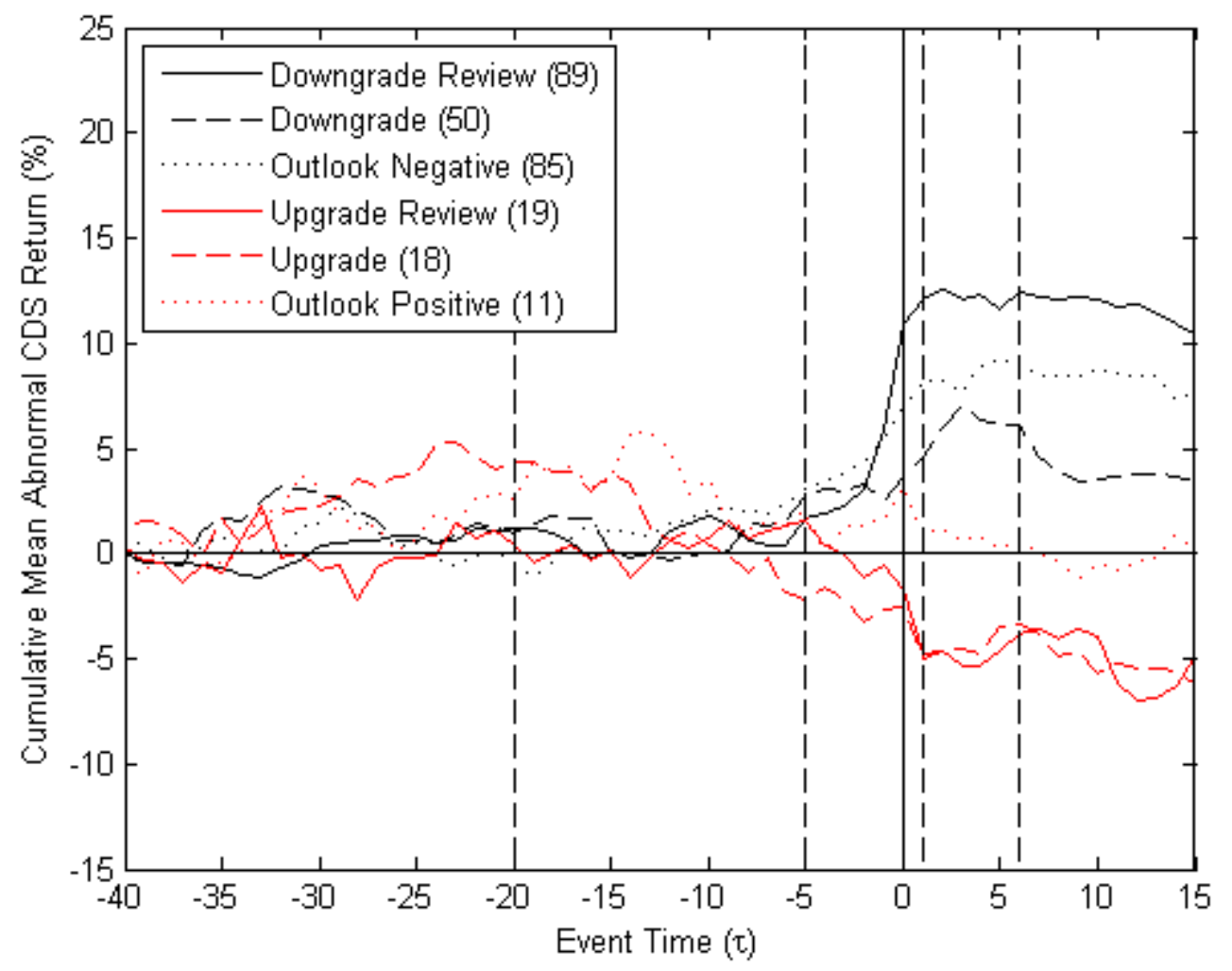


Table V: Panel A presents cumulative mean abnormal CDS returns during the post-crisis period, as given by Equation (13) in Appendix B. The results of the $\mathrm{J} 1$ test statistic in Equation $(15)$ are denoted by: $*(10 \%)$, $* *(5 \%)$ and $* * *(1 \%)$. The results of the cross-sectional bootstrap test in Equation (21) are denoted by $\dagger$ using the same convention. Panel B presents the corresponding mean standardized cumulative abnormal CDS returns, during the post-crisis period, as given by Equation (19). The equivalent results of the BMP test in Equation 20 are denoted by $\%$

Panel A: Cumulative Mean Abnormal CDS Returns (\%)

Event Window Subdivision

\begin{tabular}{lcccccc}
\cline { 2 - 7 } Announcement & {$[-40,-21]$} & {$[-20,-6]$} & {$[-5,-1]$} & {$[0]$} & {$[1,5]$} & {$[6,15]$} \\
\hline Downgrade Review & 1.09 & -0.73 & $5.50_{\dagger \dagger \dagger}^{* * *}$ & $5.08_{+\dagger}^{* * *}$ & 0.68 & -1.15 \\
Rating Downgrade & 1.19 & 0.39 & 0.85 & $1.18_{\dagger}^{*}$ & $2.52_{\dagger \dagger}^{*}$ & -2.71 \\
Outlook Negative & -0.01 & 2.42 & $3.12_{\dagger}^{* *}$ & $1.36^{* *}$ & $2.28^{*}$ & -1.41 \\
Upgrade Review & 1.02 & 0.30 & -1.9 & -1.18 & -3.00 & -0.26 \\
Rating Upgrade & 3.99 & -5.84 & -0.82 & 0.08 & -0.88 & -2.65 \\
Outlook Positive & 2.81 & 01.50 & 0.41 & 1.51 & -2.90 & -0.22 \\
\hline
\end{tabular}

Panel B: Mean Standardized Cumulative Abnormal CDS Returns

Event Window Subdivision

\begin{tabular}{|c|c|c|c|c|c|c|}
\hline Announcement & {$[-40,-21]$} & {$[-20,-6]$} & {$[-5,-1]$} & {$[0]$} & {$[1,5]$} & {$[6,15]$} \\
\hline Downgrade Review & 0.016 & 0.005 & $0.240^{\prime \prime \prime}$ & $1.310^{\prime \prime \prime}$ & 0.056 & 0.011 \\
\hline Rating Downgrade & 0.042 & 0.017 & 0.027 & $0.341^{\prime}$ & $0.131^{\prime \prime}$ & -0.075 \\
\hline Outlook Negative & 0.020 & 0.034 & 0.130 & $0.370^{\prime \prime}$ & 0.071 & -0.014 \\
\hline Upgrade Review & 0.019 & 0.005 & -0.069 & -0.068 & -0.212 & 0.001 \\
\hline Rating Upgrade & 0.053 & -0.116 & -0.056 & -0.086 & -0.070 & -0.063 \\
\hline Outlook Positive & 0.030 & -0.012 & -0.040 & 0.414 & -0.086 & -0.019 \\
\hline
\end{tabular}


Table VI: Panel A presents the results of paired difference tests on cumulative mean abnormal returns and their standardized counterparts, as defined in Equations 13 \& 19, in the week preceding rating announcements by Moody's, before and after the rating crisis. Panel B does the same for the announcement days. Significance is denoted by: $*(10 \%), * *(5 \%)$ and $* * *(1 \%)$.

Panel A: Paired Difference tests in the $[-5,-1]$ interval

\begin{tabular}{llccc} 
& & Pre-crisis & Post-crisis & Difference \\
\hline \multirow{2}{*}{ Downgrade Review } & $\overline{C A R}_{3}$ & 4.65 & 5.50 & 0.85 \\
& $\overline{S C A R}_{3}$ & 0.279 & 0.240 & -0.039 \\
Rating Downgrade & $\overline{C A R}_{3}$ & -0.72 & 0.853 & 1.57 \\
& $\overline{S C A R}_{3}$ & 0.015 & 0.027 & 0.012 \\
Outlook Negative & $\overline{C A R}_{3}$ & 0.97 & 3.12 & 2.15 \\
& $\overline{S C A R}_{3}$ & 0.081 & 0.13 & 0.050 \\
Upgrade Review & $\overline{C A R}_{3}$ & -1.95 & -1.90 & 0.05 \\
\multirow{3}{*}{ Rating Upgrade } & $\overline{S C A R}_{3}$ & -0.152 & -0.070 & 0.082 \\
& $\overline{C A R}_{3}$ & -1.13 & -0.81 & 0.32 \\
Outlook Positive & $\overline{S C A R}_{3}$ & -0.070 & -0.060 & 0.010 \\
& $\overline{C A R}_{3}$ & -1.87 & 0.41 & -2.28 \\
& $\overline{S C A R}_{3}$ & -0.100 & 0.040 & 0.140 \\
\hline
\end{tabular}

Panel B: Paired Difference tests in the [0] interval

\begin{tabular}{lcccc} 
& & Pre-crisis & Post-crisis & Difference \\
\hline \multirow{2}{*}{ Downgrade Review } & $\overline{C A R}_{4}$ & 10.1 & 5.08 & $-5.03^{*}$ \\
& $\overline{S C A R}_{4}$ & 3.170 & 1.310 & $-1.860^{* *}$ \\
Rating Downgrade & $\overline{C A R}_{4}$ & 3.34 & 1.18 & $-2.16^{*}$ \\
& $\overline{S C A R}_{4}$ & 1.000 & 0.340 & $-0.660^{* *}$ \\
Outlook Negative & $\overline{C A R}_{4}$ & 1.48 & 1.36 & -0.12 \\
& $\overline{S C A R}_{4}$ & 0.460 & 0.440 & 0.020 \\
Upgrade Review & $\overline{C A R}_{4}$ & -6.06 & -1.18 & $4.88^{*}$ \\
& $\overline{S C A R}_{4}$ & -1.760 & -0.070 & $1.690^{* *}$ \\
Rating Upgrade & $\overline{C A R}_{4}$ & -1.51 & 0.08 & -1.59 \\
& $\overline{S C A R}_{4}$ & -0.343 & -0.086 & -0.257 \\
Outlook Positive & $\overline{C A R}_{4}$ & -0.19 & 1.51 & $1.7^{*}$ \\
& $\overline{S C A R}_{4}$ & -0.061 & 0.414 & $0.474^{*}$ \\
\hline
\end{tabular}


Table VII: The results of the multivariate cross-sectional regressions of announcement day CDS performance. Panel A relates to downgrade reviews (RRD) and Panel B rating downgrades (RD). These regressions span both the pre- and post-rating crisis samples. Columns 2-4 correspond to mean standardized cumulative abnormal returns in Equation (18), Appendix B, and Columns 5-7 correspond to standardized gross spread changes in Equation (6). HAC standard errors (S.e) are reported. Significance is denoted by: * $(10 \%), * *(5 \%)$ and $* * *(1 \%)$.

Panel A: Downgrade Reviews

\begin{tabular}{lcclcll} 
& \multicolumn{3}{c}{$\widehat{S C A R}_{4}^{R R D}$} & \multicolumn{3}{c}{$S G S C_{4}^{R R D}$} \\
\cline { 2 - 7 } & Coeff. & S.e. & t-stat & Coeff. & S.e. & t-stat \\
\hline Const. & 4.13 & 0.98 & $4.21^{* * *}$ & 6.16 & 1.88 & $3.28^{* * *}$ \\
RCD & -1.53 & 0.78 & $-1.96^{* *}$ & -3.97 & 2.03 & $-1.96^{* *}$ \\
IGD & -0.55 & 0.89 & -0.62 & 1.05 & 1.76 & 0.60 \\
PNED & -1.81 & 0.57 & $-3.18^{* * *}$ & -2.17 & 1.41 & -1.54 \\
BD & -0.36 & 1.02 & -0.35 & 0.56 & 1.67 & 0.34 \\
\hline$R^{2}(\%)$ & & 7.4 & & 4.6 & \\
No. Observations & & 150 & & & & \\
\hline
\end{tabular}

Panel B: Rating Downgrades

\begin{tabular}{lcclccl} 
& \multicolumn{3}{c}{$\widehat{S C A R}_{4}^{R D}$} & \multicolumn{3}{c}{$S G S C_{4}^{R D}$} \\
\cline { 2 - 7 } & Coeff. & S.e. & t-stat & Coeff. & S.e. & t-stat \\
\hline Const. & 1.08 & 0.29 & $3.72^{* * *}$ & 0.85 & 0.28 & $3.04^{* * *}$ \\
RCD & -0.65 & 0.29 & $-2.23^{* *}$ & -0.76 & 0.33 & $-2.30^{* *}$ \\
IGD & -0.29 & 0.28 & -1.04 & -0.40 & 0.37 & -1.08 \\
PNED & 0.11 & 0.31 & 0.36 & 0.34 & 0.27 & 1.26 \\
NCD & -0.38 & 0.21 & $-1.81^{*}$ & -0.08 & 0.29 & -0.28 \\
CBD & 0.46 & 0.48 & 0.96 & 0.36 & 0.80 & 0.45 \\
\hline$R^{2}(\%)$ & & 9.2 & & & & \\
No. Observations & & 74 & & & 74 & \\
\hline
\end{tabular}


Table VIII: The results of the multivariate cross-sectional regressions of announcement day CDS performance during the post-rating crisis period. Panel A relates to downgrade reviews (RRD) and Panel B rating downgrades (RD). Columns 2-4 correspond to mean standardized cumulative abnormal returns in Equation (18), Appendix B, and Columns 5-7 correspond to standardized gross spread changes in Equation (6). HAC standard errors (S.e) are reported. Significance is denoted by: $*(10 \%), * *(5 \%)$ and $* * *(1 \%)$.

Panel A: Downgrade Reviews

\begin{tabular}{lcclccl} 
& \multicolumn{3}{c}{$\widehat{S C A R}_{4}^{R R D}$} & \multicolumn{3}{c}{$S G S C_{4}^{R R D}$} \\
\cline { 2 - 8 } & Coeff. & S.e. & t-stat & Coeff. & S.e. & t-stat \\
\hline Const. & 2.52 & 0.90 & $2.80^{* * *}$ & 2.45 & 1.22 & $2.00^{* * *}$ \\
NBERD & -0.09 & 0.77 & -0.12 & 0.06 & 1.26 & 0.05 \\
IGD & -0.39 & 0.65 & -0.60 & 0.11 & 1.05 & 0.10 \\
PNED & -1.80 & 0.52 & $-3.46^{* * *}$ & -1.54 & 0.92 & $-1.67^{*}$ \\
BD & -0.37 & 0.84 & -0.44 & 0.15 & 1.11 & 0.14 \\
\hline$R^{2}(\%)$ & \multicolumn{3}{c}{11.2} & & 3.9 & \\
No. Observations & \multicolumn{3}{c}{89} & & & \\
\hline
\end{tabular}

Panel B: Rating Downgrades

\begin{tabular}{lcclccc} 
& \multicolumn{3}{c}{$\widehat{S C A R}_{4}^{R D}$} & \multicolumn{3}{c}{$S G S C_{4}^{R D}$} \\
\cline { 2 - 8 } & Coeff. & S.e. & t-stat & Coeff. & S.e. & t-stat \\
\hline Const. & 1.14 & 0.45 & $2.53^{* * *}$ & 0.66 & 0.46 & 1.43 \\
NBERD & -0.76 & 0.47 & -1.61 & -0.64 & 0.48 & -1.33 \\
IGD & -0.23 & 0.36 & -0.64 & -0.35 & 0.53 & 0.66 \\
PNED & -0.22 & 0.33 & -0.67 & 0.06 & 0.26 & 0.23 \\
NCD & -0.31 & 0.32 & -0.97 & 0.05 & 0.41 & 0.12 \\
CBD & 0.72 & 0.55 & 1.31 & 0.68 & 1.06 & 0.64 \\
\hline$R^{2}(\%)$ & \multicolumn{3}{c}{11.9} & & & \\
No. Observations & & 50 & & & 50 & \\
\hline
\end{tabular}




\section{References}

Adelino, M.: 2009, Do investors only rely on ratings? the case of mortgage-backed securities, Working paper.

Benmelech, E. and Dlugosz, J.: 2009, The credit rating crisis, NBER Macroeconomics Annual .

Berndt, A. and Obreja, I.: 2010, Decomposing european cds returns, Review of Finance 14(2), 189233.

Bhanot, K. and Mello, A. S.: 2006, Should corporate debt include a rating trigger?, Journal of Financial Economics 79(1), 69-98.

Binder, J.: 1998, The event study methodology since 1969, Review of Quantitative Finance and Accounting 11, 113-137.

Blanco, R., Brennan, S. and Marsh, I.: 2005, An empirical analysis of the dynamic relation between investment-grade bonds and credit default swaps, Journal of Finance 60(5), 22552281.

Boehmer, E., Musumeci, J. and Poulsen, A. B.: 1991, Event-study methodology under conditions of event-induced variance, Journal of Financial Economics 30, 253-272.

Bongaerts, D., Cremers, K. M. and Goetzmann, W.: 2009, Tiebreaker: Certification and multiple credit ratings, Journal of Finance, forthcoming .

Brunnermeier, M.: 2009, Deciphering the liquidity and credit cruch 2007-2008, Journal of Economic Perspectives 23(1), 77-100.

Campbell, J. Y., Lo, A. W. and MacKinlay, A. C.: 1997, The Econometrics of Financial Markets, Princeton University Press.

Cathcart, L., El-Jahel, L. and Evans, L.: 2010, The correlation structure of the cds market: An empirical investigation, Working Paper.

Coval, J., Jurek, J. and Stafford, E.: 2009, The economics of structured finance, Journal of Economic Perspectives 23(1), 3-25.

Daniels, K. N. and Jensen, M. S.: 2005, The effect of credit ratings on credit default swap spreads and credit spreads, Journal of Fixed Income 15(3), 16-33.

Duffie, D.: 1999, Credit swap valuation, Financial Analysts Journal 55(1), 73-87.

Efron, B. and Tibshirani, R. J.: 1993, An Introduction to the Bootstrap, Chapman \& Hall.

Elton, E., Gruber, M., Agrawal, D. and Mann, C.: 2001, Explaining the rate spread on corporate bonds, Journal of Finance 56(1), 247-277.

Financial Crisis Inquiry Commission: 2010, Credit ratings and the financial crisis, Technical report.

Goh, J. C. and Ederington, L. H.: 1993, Is a bond rating downgrade bad news, good news or no news for stockholders?, Journal of Finance 48(5), 2001-2008.

Griffin, J. M. and Tang, D. Y.: 2010, Did subjectivity play a role in cdo credit ratings?, Working paper. 
Hand, J. R. M., Holhausen, R. W. and Leftwich, R. W.: 1992, The effect of bond rating agency announcements on bond and stock prices, Journal of Finance 47(2), 733-752.

Harrington, S. E. and Shrider, D. G.: 2007, All events induce variance: Analyzing abnormal returns when effects vary across firms, Journal of Financial and Quantitative Analysis 42(1), 229256.

Holthausen, R. W. and Leftwich, R. W.: 1986, The effect of bond rating changes on common stock prices, Journal of Financial Economics 17(1), 57 - 89.

Houweling, P. and Vorst, T.: 2005, Pricing default swaps: empirical evidence, Journal of International Money and Finance 24, 1200-1225.

Hull, J., Predescu, M. and White, A.: 2004, The relationship between credit default swap spreads, bond yields and credit rating announcements, Journal of Banking \& Finance 28, 2789-2811.

Jorion, P., Liu, Z. and Shi, C.: 2005, Informational effects of regulation fd: evidence from rating agencies, Journal of Financial Economics 76, 309-330.

Jorion, P. and Zhang, G.: 2007, Good and bad credit contagion: Evidence from credit default swaps, Journal of Financial Economics 84(3), 860-883.

Kisgen, D. J.: 2006, Credit ratings and capital structure, Journal of Finance 61, 1035-1072.

Kisgen, D. J. and Strahan, P. E.: 2009, Do regulations based on credit ratings affect a firm's cost of capital?, Review of Financial Studies, forthcoming .

Longstaff, F., Mithal, S. and Neis, E.: 2005, Corporate yield spreads: Default risk or liquidity? new evidence from the credit default swap market, Journal of Finance 60(5), 2213-2253.

Mason, J. R. and Rosner, J.: 2007, Where did the risk go? how misapplied bond ratings cause mortgage backed securities and collateralized debt obligation market disruptions, Working paper.

Micu, M., Remolona, E. and Wooldridge, P.: 2006, The price impact of rating announcements: which announcements matter? BIS working papers.

Moody's: 2002, Understanding moodys corporate bond ratings and rating process, Technical report, Moody's Investors Service.

Norden, L.: 2008, Credit derivatives, corporate news and credit ratings, Working paper .

Norden, L. and Weber, M.: 2004, Informational efficiency of credit default swap and stock markets: The impact of credit rating announcements, Journal of Banking \& Finance 28, 2789-2811.

Pagano, M. and Volpin, P.: 2010, Credit rating failures and policy options, Economic Policy 25, 401-431.

Patell, J. M.: 1976, Corporate forecasts of earnings per share and stock price behavious: Empirical tests, Journal of Accounting Research 14, 246-276.

Perraudin, W. and Taylor, A. P.: 2004, On the consistency of ratings and bond market yields, Journal of Banking \& Finance 28, 2769-2788.

Standard \& Poor's: 2007, Principles-based rating methodology for global structured finance securities, Technical report, Ratings Direct Research. 
Steiner, M. and Heinke, V. G.: 2001, Event study concerning international bond price effects of credit rating actions, International Journal of Finance and Economics 6, 139-157.

The Joint Forum: 2009, Stocktaking on the use of credit ratings, Technical report, Basel Committee on Banking Supervision.

White, L. J.: 2010, Markets: The credit rating agencies, Journal of Economic Perspectives 24(2), $1-16$. 


\section{A. List of Firms}

The 205 issuers whose CDS prices and Moody's corporate rating announcement data are considered in the study. They are grouped into 10 economic sectors as defined by the GICS. Av. Rat. corresponds the the average rating of the issuer on the period September 14, 2004 to December 14, 2009.

\begin{tabular}{|c|c|c|c|c|c|}
\hline Sector & Issuer & Av. Rat. & Sector & Issuer & Av. Rat. \\
\hline \multirow[t]{28}{*}{ Financials } & Allstate Corp. & $\mathrm{A} 1$ & Consumer & American Axle\&Mnfg Inc. & B1 \\
\hline & Ambac Financial Gp. Inc. & $\mathrm{A} 2$ & Discretionary & Arvinmeritor Inc. & B1 \\
\hline & American Express Co. & $\mathrm{A} 1$ & & Beazer Homes USA Inc. & $\mathrm{Ba} 3$ \\
\hline & American Intl. Gp. & $\mathrm{Aa} 3$ & & Black\&Decker Corp. & Baa2 \\
\hline & Aon Corp. & $\mathrm{Baa} 2$ & & Block Financial Corp. & A3 \\
\hline & Avalonbay Commns. Inc. & Baa1 & & Borgwarner Inc. & Baa2 \\
\hline & Bank Of America Corp. & $\mathrm{Aa} 2$ & & Brunswick Corp. & Baa3 \\
\hline & Capital One Bank & A3 & & Cablevision Systems Corp. & B3 \\
\hline & Citigroup Inc. & $\mathrm{Aa} 2$ & & Carnival Corp. & A3 \\
\hline & Goldman Sachs Gp. Inc. & Aa3 & & Cooper Tire\&Rubber & B1 \\
\hline & Hartford Finl.Svs.Gp. & A3 & & D.R.Horton Inc. & $\mathrm{Ba} 1$ \\
\hline & JPMorgan Chase\&Co. & $\mathrm{Aa} 3$ & & Eastman Kodak Co. & B1 \\
\hline & Kimco Realty Corp. & Baa1 & & Gannett Co. Inc. & A3 \\
\hline & Lincoln National Corp. & A3 & & Goodyear Tire\&Rub. Co. & B2 \\
\hline & Loews Corp. & A3 & & Hasbro Inc. & $\mathrm{Baa} 3$ \\
\hline & MBIA Inc. & $\mathrm{A} 1$ & & Interpublic Gp.Cos. Inc. & $\mathrm{Ba} 2$ \\
\hline & MetLife Inc. & A2 & & J.C. Penney Co. Inc. & Ba1 \\
\hline & MGIC Investment Corp. & A3 & & Johnson Controls Inc. & Baa1 \\
\hline & Morgan Stanley Gp. Inc. & $\mathrm{Aa} 3$ & & Jones Apparel Gp. Inc. & $\mathrm{Baa} 3$ \\
\hline & PMI Group Inc. & A3 & & KB Home & $\mathrm{Ba} 2$ \\
\hline & Prologis Trust & Baal & & Lennar Corp. & $\mathrm{Ba} 1$ \\
\hline & Prudential Financial Inc. & A3 & & Liz Claiborne Inc. & Baa3 \\
\hline & Radian Group Inc. & Baa1 & & Lowe's Companies Inc. & A1 \\
\hline & SLM Corp. & A3 & & Limited Brands Inc. & Baa3 \\
\hline & The Travelers Cos. Inc. & A3 & & Macy's Inc. & $\mathrm{Ba} 3$ \\
\hline & Unum Group & $\mathrm{Ba} 1$ & & Marriott Intl. Inc. & Baa2 \\
\hline & Wells Fargo\&Co. & Aa1 & & Mattel Inc. & $\mathrm{Baa} 2$ \\
\hline & XL Capital Ltd. & A3 & & M.D.C Holdings Inc. & Baa3 \\
\hline \multirow[t]{23}{*}{ Materials } & Ak Steel Corp. & B1 & & MGM Mirage Inc. & $\mathrm{Ba} 3$ \\
\hline & Alcoa Inc. & A3 & & Newell Rubbermaid Inc. & $\mathrm{Baa} 2$ \\
\hline & Ashland Inc. & Ba1 & & Nordstrom Inc. & Baa1 \\
\hline & Commercial Metals Co. & Baa2 & & Omnicom Group & Baa1 \\
\hline & Cytec Industries Inc. & $\mathrm{Baa} 3$ & & Pulte Homes Inc. & Bal \\
\hline & Dow Chemical Co. & A3 & & Radioshack Corp. & Baa3 \\
\hline & E.I. du Pont de Nemours & $\mathrm{A} 2$ & & Royal Crbn. Cruises Ltd. & $\mathrm{Ba} 1$ \\
\hline & International Paper Co. & Baa3 & & Ryland Group Inc. & $\mathrm{Ba} 1$ \\
\hline & Louisiana-Pacific Corp. & Ba1 & & Sherwin-Williams Co. & A3 \\
\hline & Lubrizol Corp. & Baa3 & & Standard Pacific Corp. & $\mathrm{Ba} 3$ \\
\hline & Martin Marietta Materials Inc. & Baa1 & & Staples Inc. & Baa1 \\
\hline & Meadwestvaco Corp. & Baa3 & & Starwood Htls.\&Rsts. Wwd. & $\mathrm{Ba} 1$ \\
\hline & Monsanto Company & A3 & & Target Corp. & A2 \\
\hline & Newmont Mining Corp. & Baal & & Time Warner Inc. & $\mathrm{Baa} 2$ \\
\hline & Nucor Corp. & A1 & & The TJX Companies Inc. & A3 \\
\hline & Olin Corp. & Baa3 & & Toll Brothers Inc. & $\mathrm{Ba} 1$ \\
\hline & Owens-Illinois Inc. & B3 & & The Walt Disney Co. & $\mathrm{A} 3$ \\
\hline & Polyone Corp. & B2 & & Wendys Intl. Inc. & $\mathrm{Ba} 2$ \\
\hline & PPG Industries Inc. & $\mathrm{A} 2$ & & Whirlpool Corp. & $\mathrm{Baa} 2$ \\
\hline & Praxair Inc. & A2 & & Yum! Brands Inc. & Baa3 \\
\hline & Sealed Air Corp. & Baa3 & Telcom. Services & AT\&T Corp. & Baal \\
\hline & Temple-Inland Inc. & Baa3 & & CenturyTel Inc. & Baa2 \\
\hline & Weyerhaeuser Company & $\mathrm{Baa} 2$ & & Sprint Nextel Corp. & $\mathrm{Baa} 3$ \\
\hline
\end{tabular}




\begin{tabular}{|c|c|c|c|c|c|}
\hline Sector & Issuer & Av. Rat. & Sector & Issuer & Av. Rat. \\
\hline \multirow[t]{17}{*}{ Energy } & Anadarko Petroleum Corp. & $\mathrm{Baa} 2$ & Consumer & Altria Group Inc. & Baal \\
\hline & Chesapeake Energy Corp. & $\mathrm{Ba} 3$ & Staples & Anheuser-Busch Cos. Inc. & $\mathrm{A} 2$ \\
\hline & ConocoPhillips & A1 & & Avon Products & $\mathrm{A} 2$ \\
\hline & Devon Energy Corp. & $\mathrm{Baa} 2$ & & Campbell Soup Co. & $\mathrm{A} 3$ \\
\hline & Diamond Offshore Drilling Inc. & $\mathrm{Baa} 2$ & & The Coca-Cola Company & $\mathrm{Aa} 3$ \\
\hline & El Paso Corp. & B2 & & ConAgra Foods Inc. & $\mathrm{Baa} 2$ \\
\hline & Halliburton Company & A3 & & CVS Caremark Corp. & Baa1 \\
\hline & Hess Corp. & Baa3 & & Dean Foods Company & B1 \\
\hline & Kinder Morgan Energy Prns. LP & Baal & & H.J. Heinz Company & Baa1 \\
\hline & Nabors Industries Inc. & $\mathrm{A} 3$ & & Kimberly-Clark Corp. & A1 \\
\hline & Occidental Petroleum Corp. & A3 & & Kraft Foods Inc. & Baa1 \\
\hline & Sunoco Inc. & $\mathrm{Baa} 2$ & & Pepsico Inc. & $\mathrm{Aa} 3$ \\
\hline & Tesoro Corp. & Bal & & Procter\&Gamble Company & $\mathrm{Aa} 3$ \\
\hline & Transocean Inc. & $\mathrm{Baa} 2$ & & Reynolds American Inc. & $\mathrm{Ba} 2$ \\
\hline & Valero Energy Corp. & $\mathrm{Baa} 3$ & & Rite Aid Corp. & Caa1 \\
\hline & Williams Companies Inc. & $\mathrm{Ba} 2$ & & Sara Lee Corp. & Baa1 \\
\hline & XTO Energy Inc. & $\mathrm{Baa} 2$ & & Smithfield Foods Inc. & $\mathrm{Ba} 3$ \\
\hline \multirow[t]{22}{*}{ Industrials } & 3M Company & Aa1 & & Supervalu Inc. & $\mathrm{Ba} 3$ \\
\hline & Avis Budget Group Inc. & B1 & & Tyson Foods Inc. & $\mathrm{Ba} 2$ \\
\hline & The Boeing Company & $\mathrm{A} 2$ & Health Care & Abbott Laboratories & A1 \\
\hline & Burlington Nth. Snt. Fe Corp. & Baa1 & & Aetna Inc. & A3 \\
\hline & Caterpillar Inc. & A2 & & AmerisourceBergen Corp. & $\mathrm{Ba} 1$ \\
\hline & Con-Way Inc. & $\mathrm{Baa} 3$ & & Amgen Inc. & $\mathrm{A} 2$ \\
\hline & Cummins Inc. & Bal & & Boston Scientific Corp. & Baa3 \\
\hline & Danaher Corp. & $\mathrm{A} 2$ & & Bristol-Myers Squibb Co. & A2 \\
\hline & Deere\&Company & $\mathrm{A} 2$ & & Cardinal Health Inc. & $\mathrm{Baa} 2$ \\
\hline & Eaton Corp. & $\mathrm{A} 2$ & & Cigna Corp. & $\mathrm{Baa} 2$ \\
\hline & Goodrich Corp. & Baa3 & & Eli Lilly\&Co. & Aa3 \\
\hline & Lockheed Martin Corp. & Baal & & McKesson Corp. & $\mathrm{Baa} 3$ \\
\hline & Masco Corp. & $\mathrm{Baa} 2$ & & Medco Health Solutions Inc. & $\mathrm{Baa} 3$ \\
\hline & Norfolk Southern Corp. & Baal & & Merck\&Co. Inc. & Baa1 \\
\hline & Northrop Grumman Corp. & $\mathrm{Baa} 2$ & & Pfizer Inc. & Aa1 \\
\hline & Pitney Bowes Inc. & $\mathrm{Aa} 3$ & & Quest Diagnostics. & $\mathrm{Baa} 2$ \\
\hline & Raytheon Company & $\mathrm{Baa} 2$ & & Tenet Healthcare Corp. & $\mathrm{Caa} 1$ \\
\hline & Republic Services Inc. & $\mathrm{Baa} 2$ & & UnitedHealth Group Inc. & A3 \\
\hline & Southwest Airlines & Baal & & Universal Health Svs. Inc. & Baa3 \\
\hline & Textron Inc. & $\mathrm{A} 3$ & & WellPoint Inc. & Baa1 \\
\hline & United Parcel Services Inc. & Aa1 & & Wyeth Limited & A3 \\
\hline & Waste Management Inc. & Baa3 & Utilities & The AES Corp. & B1 \\
\hline \multirow[t]{13}{*}{ IT } & Advanced Micro Devices Inc. & B2 & & Allegheny Engy. Supp. Co. LLC. & $\mathrm{Ba} 2$ \\
\hline & Amkor Technology Inc. & $\mathrm{B} 2$ & & American Elec. Pwr. Co. Inc. & $\mathrm{Baa} 2$ \\
\hline & Arrow Electronics Inc. & $\mathrm{Baa} 3$ & & CenterPoint Energy Inc. & Ba1 \\
\hline & Avnet Inc. & $\mathrm{Ba} 1$ & & CMS Energy Corp. & $\mathrm{Ba} 3$ \\
\hline & CA Inc. & $\mathrm{Ba} 1$ & & Constellation En. Gp. Inc. & Baa1 \\
\hline & Computer Sciences Corp. & $\mathrm{A} 3$ & & Dominion Resources Inc. & $\mathrm{a} 22$ \\
\hline & Corning Inc. & Baa2 & & DPL Inc. & Baa3 \\
\hline & Hewlett-Packard Company & A2 & & Duke Energy Carolinas LLC. & A3 \\
\hline & Motorola Inc. & $\mathrm{Baa} 2$ & & Dynegy Inc. & B1 \\
\hline & Sun Microsystems Inc. & Ba1 & & ONEOK Inc. & $\mathrm{Baa} 2$ \\
\hline & Unisys Corp. & B1 & & Pepco Holdings Inc. & Baa3 \\
\hline & Xerox Corp. & $\mathrm{Baa} 3$ & & Progress Energy Inc. & $\mathrm{Baa} 2$ \\
\hline & Teco Energy Inc. & Ba1 & & & \\
\hline
\end{tabular}




\section{B. Event Study Test Statistics}

It can be shown ${ }^{27}$ that conditional on the market return over the event window, abnormal CDS returns in Equation 3 will be jointly normally distributed with zero conditional mean and conditional covariance matrix $\mathbf{V}_{\mathbf{i}}$. Under the null hypothesis that rating announcements have no impact on the mean or variance of CDS returns:

$$
\widehat{\mathbf{A R}}_{\mathbf{i}}^{*} \sim N\left(0, \mathbf{V}_{\mathbf{i}}\right)
$$

Where:

$$
\mathbf{V}_{\mathrm{i}}=\mathbf{I} \sigma_{\varepsilon_{\mathrm{i}}}^{2}+\mathbf{X}_{\mathbf{i}}^{*}\left(\mathbf{X}_{\mathbf{i}}^{\prime} \mathbf{X}_{\mathbf{i}}\right)^{-1} \mathbf{X}_{\mathbf{i}}^{* \prime} \sigma_{\varepsilon_{\mathrm{i}}}^{2}
$$

In order to draw overall inference for a particular type of rating announcement, individual securities' abnormal return vectors $\widehat{\mathbf{A R}}_{\mathbf{i}}^{*}$ are aggregated across securities and through time. We first cross-sectionally average:

$$
\overline{\mathbf{A R}}^{*}=\frac{1}{\mathrm{~N}} \sum_{\mathrm{i}=1}^{\mathrm{N}} \widehat{\mathbf{A R}}_{\mathbf{i}}^{*}
$$

By assuming that the event windows of the $N$ announcements do not overlap in calendar time, one may set the covariance terms equal to zero to give ${ }^{28}$ :

$$
\operatorname{Var}\left[\overline{\mathbf{A R}}^{*}\right]=\mathbf{V}=\frac{1}{\mathrm{~N}^{2}} \sum_{\mathrm{i}=1}^{\mathrm{N}} \mathbf{V}_{\mathbf{i}}
$$

We then temporally aggregate average abnormal returns by defining $\overline{C A R}_{k}\left(\tau_{1}, \tau_{2}\right)$ as the cumulative average abnormal return from $\tau_{1}$ to $\tau_{2}$ where $T_{1}<\tau_{1}<\tau_{2} \leqslant T_{2}$ are the cut-off points of the $k=$ $1,2, . ., 6$ event window intervals given in Section III. By defining $\gamma_{\mathrm{k}}$ as an $\left(L_{2} \times 1\right)$ vector with ones in positions $\tau_{1}-T_{1}$ to $\tau_{2}-T_{1}$ and zeros everywhere else:

$$
\overline{C A R}_{k}\left(\tau_{1}, \tau_{2}\right) \equiv \gamma_{k} \overline{\mathbf{A R}}^{*} \sim N\left(0, \bar{\sigma}_{\mathrm{k}}^{2}\left(\tau_{1}, \tau_{2}\right)\right)
$$

\footnotetext{
${ }^{27}$ See Campbell, Lo and MacKinlay (1997).

${ }^{28}$ Assuming cross-sectional independence of the residuals ignores industry and rating classification effects noted by Cathcart et al. (2010) for firms with the same event windows in calendar time. However, our sample consists of a broad cross-section of firms with a balanced distribution across industries and ratings. Also our events are not highly clustered in calendar time.
} 
Where:

$$
\bar{\sigma}_{\mathrm{k}}^{2}\left(\tau_{1}, \tau_{2}\right)=\operatorname{Var}\left[\overline{\operatorname{CAR}}_{\mathrm{k}}\left(\tau_{1}, \tau_{2}\right)\right]=\gamma_{\mathrm{k}}^{\prime} \mathbf{V} \gamma_{\mathrm{k}}
$$

The $J_{1}$ statistic of Campbell et al. (1997) is:

$$
J_{1}^{k}=\frac{\overline{C A R}_{k}\left(\tau_{1}, \tau_{2}\right)}{\left[\hat{\bar{\sigma}}_{\mathrm{k}}^{2}\left(\tau_{1}, \tau_{2}\right)\right]^{\frac{1}{2}}}
$$

However, this statistic relies on the residual variance estimate from the market model to estimate the variance of the abnormal return estimator ${ }^{29}$. As highlighted by Binder (1998) this will likely underestimate the true variance due to event-induced heteroskedasticity; the event day return is a function of both the random announcement shock as well as other firm-specific shocks. Harrington and Shrider (2007) argue that tests robust to cross-sectional variation in true abnormal returns should always be used in event studies and that a good candidate for a robust parametric test is the standardized cross-sectional test statistic of Boehmer, Musumeci and Poulsen (1991). By defining the cumulative abnormal return for security $i$ as:

$$
\begin{gathered}
\widehat{C A R}_{i, k}\left(\tau_{1}, \tau_{2}\right) \equiv \gamma_{\mathrm{k}}^{\prime} \widehat{\mathbf{A R}}_{\mathbf{i}}^{*} \\
\sigma_{\mathrm{i}, \mathrm{k}}^{2}\left(\tau_{1}, \tau_{2}\right)=\operatorname{Var}\left[\widehat{\mathrm{CAR}}_{\mathrm{i}, \mathrm{k}}\left(\tau_{1}, \tau_{2}\right)\right]=\gamma_{\mathrm{k}}^{\prime} \mathbf{V}_{\mathrm{i}} \gamma_{\mathrm{k}}
\end{gathered}
$$

The cumulative abnormal return estimates are first standardized by their estimated standard deviation, adjusted for forecast error:

$$
\widehat{\operatorname{SCAR}}_{i, k}\left(\tau_{1}, \tau_{2}\right)=\frac{\widehat{C A R}_{i, k}\left(\tau_{1}, \tau_{2}\right)}{\hat{\sigma}_{i, k}\left(\tau_{1}, \tau_{2}\right)}
$$

\footnotetext{
${ }^{29}$ Since $\bar{\sigma}_{\mathrm{k}}^{2}\left(\tau_{1}, \tau_{2}\right)$ is unknown, we use the OLS estimator of the estimation-window residual variance $\hat{\sigma}_{\varepsilon_{i}}^{2}=\frac{1}{L_{1}-2} \hat{\varepsilon}_{i}^{\prime} \hat{\varepsilon}_{i}$ to calculate the variance of abnormal returns in Equation [10, with the specified adjustment for forecast error explained in Patell (1976).
} 
This stops securities with large variances from dominating the test. By defining $\overline{\operatorname{SCAR}}_{k}\left(\tau_{1}, \tau_{2}\right)$ as the cross-sectional mean standardized cumulative abnormal return in a given event window subinterval:

$$
\overline{\operatorname{SCAR}}_{k}\left(\tau_{1}, \tau_{2}\right)=\frac{1}{N} \sum_{i=1}^{N} \widehat{\operatorname{SCAR}}_{i, k}\left(\tau_{1}, \tau_{2}\right)
$$

The Boehmer, Musumeci and Poulsen (1991) (BMP) standardized cross-sectional statistic is calculated as:

$$
t_{B M P}^{k}=\sqrt{N} \frac{\overline{S C A R}_{k}\left(\tau_{1}, \tau_{2}\right)}{\sqrt{\frac{1}{(N-1)} \sum_{i=1}^{N}\left(\widehat{S C A R}_{i, k}\left(\tau_{1}, \tau_{2}\right)-\overline{S C A R}_{k}\left(\tau_{1}, \tau_{2}\right)\right)^{2}}}
$$

Finally, as a robustness check on the parametric tests, we also make use of a non-parametric bootstrapped cross-sectional test statistic (See Efron and Tibshirani (1993)) on cumulative average abnormal CDS returns. Here, we continue to utilize the information in the cross-section to form the Bootstrap (BST) statistic:

$$
t_{B S T}^{k}=\sqrt{N} \frac{\overline{C A R}_{k}\left(\tau_{1}, \tau_{2}\right)}{\sqrt{\frac{1}{(N-1)} \sum_{i=1}^{N}\left(\widehat{C A R}_{i, k}\left(\tau_{1}, \tau_{2}\right)-\overline{C A R}_{k}\left(\tau_{1}, \tau_{2}\right)\right)^{2}}}
$$

We proceed as follows: Define $\widetilde{C A R}_{i, k}\left(\tau_{1}, \tau_{2}\right)=\widehat{C A R}_{i, k}\left(\tau_{1}, \tau_{2}\right)-\overline{C A R}_{k}\left(\tau_{1}, \tau_{2}\right)$ for $i=1,2, . ., N$ and, for a given $\mathrm{k}$, the values of which correspond to the distribution defined by the null hypothesis of the test, or null distribution. We sample with replacement $N$ times from the null distribution, calculate the sample mean $\left(\bar{s}^{B}\right)$, standard deviation $\left(\hat{\sigma}^{B}\right)$ and t-statistic $t^{B}=\sqrt{n}\left(\bar{s}^{B} / \hat{\sigma}^{B}\right)$ for a total of $B=99,999$ bootstrap samples. This provides the empirical distribution for $t$ under the null hypothesis. 